\title{
Alterations in Left Ventricular Diastolic Function in Conscious Dogs with Pacing-induced Heart Failure
}

\author{
Kazuo Komamura, Richard P. Shannon, Ares Pasipoularides, Tadashi Ihara, Alan S. Lader, \\ Thomas A. Patrick, Sanford P. Bishop, and Stephen F. Vatner \\ Department of Medicine, Harvard Medical School, Beth Israel, and Brigham and Women's Hospitals, Boston, Massachusetts 02115; \\ and New England Regional Primate Research Center, Southborough, Massachusetts 01772
}

\begin{abstract}
We investigated in conscious dogs $(a)$ the effects of heart failure induced by chronic rapid ventricular pacing on the sequence of development of left ventricular (LV) diastolic versus systolic dysfunction and $(b)$ whether the changes were load dependent or secondary to alterations in structure. $\mathrm{LV}$ systolic and diastolic dysfunction were evident within $24 \mathrm{~h}$ after initiation of pacing and occurred in parallel over 3 wk. LV systolic function was reduced at 3 wk, i.e., peak $L V \mathrm{dP} / \mathrm{d} t$ fell by $-1,327 \pm 105$ $\mathrm{mmHg} / \mathrm{s}$ and ejection fraction by $-22 \pm 2 \%$. $\mathrm{LV}$ diastolic dysfunction also progressed over 3 wk of pacing, i.e., $\tau$ increased by $+14.0 \pm 2.8 \mathrm{~ms}$ and the myocardial stiffness constant by $+6.5 \pm 1.4$, whereas LV chamber stiffness did not change. These alterations were associated with increases in $\mathrm{LV}$ endsystolic $\left(+28.6 \pm 5.7 \mathrm{~g} / \mathrm{cm}^{2}\right)$ and $\mathrm{LV}$ end-diastolic stresses $\left(+40.4 \pm 5.3 \mathrm{~g} / \mathrm{cm}^{2}\right)$. When stresses and heart rate were matched at the same levels in the control and failure states, the increases in $\tau$ and myocardial stiffness were no longer observed, whereas $L V$ systolic function remained depressed. There were no increases in connective tissue content in heart failure. Thus, pacing-induced heart failure in conscious dogs is characterized by major alterations in diastolic function which are reversible with normalization of increased loading condition. (J. Clin. Invest. 1992. 89:1825-1838.) Key words: collagen - diastole • heart failure $\bullet$ rapid pacing $\bullet$ ventricular function
\end{abstract}

\section{Introduction}

Congestive heart failure is characterized by impairment of both systolic and diastolic left ventricular $(\mathrm{LV})^{1}$ function $(1,2)$. Some studies have suggested that the alterations in diastolic function may even precede impairment of systolic function (3-5). Diastolic dysfunction could be due to a defect in the cardiac myocytes, to altered intracellular calcium handling, to alterations in structure, e.g., collagen content, to alterations in

Dr. Pasipoularides is with the Department of Biomedical Engineering, Duke University, Durham, NC 27705; Dr. Bishop is with the Department of Pathology, University of Alabama, Birmingham, AL 35294.

Address reprint requests to Dr. Vatner, New England Regional Primate Research Center, P.O. Box 9102, Southborough, MA 017729102.

Received for publication 4 September 1991 and in revised form 3 January 1992.

1. Abbreviations used in this paper: $\mathrm{LV}$, left ventricular; $\mathrm{RV}$, right ventricular.

J. Clin. Invest.

(c) The American Society for Clinical Investigation, Inc.

$0021-9738 / 92 / 06 / 1825 / 14 \$ 2.00$

Volume 89, June 1992, 1825-1838 loading conditions, or to concomitant myocardial ischemia. These factors are associated frequently with the diastolic dysfunction observed in human heart failure, and are generally inseparable in most chronic models of heart failure, particularly in the clinical setting $(1,2)$. In order to elucidate which of these mechanisms are important in mediating diastolic dysfunction during the development of heart failure and to determine whether alterations in diastolic function precede or follow alterations in systolic function, it is important to examine an experimental model in which the changes in systolic and diastolic function can be assessed longitudinally as the congestive heart failure state is induced, and potentially be studied early enough such that alterations in collagen content are not a confounding factor $(6,7)$. The model of pacing-induced cardiomyopathy and heart failure is ideal for this investigation because it has been well characterized in terms of its alterations in LV systolic function (8-12), has been shown to be characterized by LV diastolic dysfunction as well (12), and can be studied as the lesion develops initially and progressively in the same animals, which serve as their own controls.

Accordingly, the goals of the current investigation were to determine in the model of pacing-induced heart failure whether alterations in LV systolic or diastolic function occurred independently of one another. Secondly, we sought to determine whether the alterations in LV systolic or diastolic function were reversible by correcting abnormal loading conditions. To accomplish these goals we studied the same chronically instrumented conscious animals 2-3 wk after recovery from surgery when they were healthy and restudied them at $1 \mathrm{~d}$ and at selected intervals for up to $3 \mathrm{wk}$ as congestive heart failure evolved. At that time, animals were sacrificed for examination of myocardial collagen content. Both in the control state and after 3 wk of pacing, loading conditions were altered such that LV systolic and diastolic function could be examined with matched preload and afterload in the control and the heart failure states.

\section{Methods}

Instrumentation (11, 13-18). 13 mongrel dogs of either sex, weighing between 22 and $34 \mathrm{~kg}$, were sedated with xylazine $(2 \mathrm{mg} / \mathrm{kg}, \mathrm{i} . \mathrm{m}$.) and anesthetized using halothane anesthesia ( $1 \mathrm{vol} \%)$. With the use of sterile technique and through an incision in the left fifth intercostal space, catheters (Tygon; Norton Plastics and Synthetic Div., Akron, $\mathrm{OH}$ ) were implanted in the descending thoracic aorta, left ventricle, left atrium, and right atrium. In all dogs, piezoelectric ultrasonic dimension crystals were implanted on opposing anterior and posterior endocardial surfaces of the left ventricle to measure the internal short axis, and on opposing endocardial and epicardial surfaces to measure wall thickness in the same equatorial plane as the internal short-axis diameter crystals. The subendocardial wall thickness crystal was implanted obliquely to avoid damage to the myocardium between the two wall thickness crystals. Ultrasonic transducers were also implanted at the basal epicardial surface and apical endocardial surface to measure LV 
long axis. A solid-state miniature pressure transducer (P22, Königsberg Instruments, Pasadena, CA) was implanted in the apex to measure LV pressure and a screw-in type pacing lead (model 4312, CPI, St. Paul, $\mathrm{MN}$ ) was attached to the RV free wall in all dogs. Seven of the dogs were instrumented additionally with an aortic occluder and an inferior vena caval occluder (Hazen-Everett, Teaneck, NJ). The pericardium was incised widely, catheters and leads were externalized infrascapularly, and the thoracotomy was closed. Fig. 1 is a representative illustration of the instrumentation employed. Another group of 13 dogs served as sham-operated controls. All dogs were allowed to recover for 2-3 wk after operation and before experimentation. The animals used in this study were maintained in accordance with the guidelines for the "Care and Use of Laboratory Animals" of the Institute of Laboratory Animal Resources, National Council (DHHS Publication No. [NIH] 85-23, revised 1985), and the Standing Committee on Animal Care of Harvard Medical School.

Aortic, left atrial, and right atrial pressures were sampled from chronically implanted catheters, and measured with strain gauge manometers (P23 ID, Statham Instruments, Oxford, CA), which were calibrated with a mercury manometer. LV pressure was measured using the solid-state miniature gauge calibrated in vitro with a mercury manometer, and in vivo using the left atrial and aortic catheters and Statham strain gauge manometers. An ultrasonic dimension gauge was used to measure $\mathrm{LV}$ dimensions. The dimension gauge generates a voltage linearly proportional to the transit time of ultrasonic impulses traveling at the velocity of $1.58 \times 10^{6} \mathrm{~mm} / \mathrm{s}$ between the $3-\mathrm{mHz}$ crystals. At constant room temperature, the thermal drift of the instrument is minimal, i.e., $<0.02 \mathrm{~mm}$ in $6 \mathrm{~h}$. Any drift in the measurement system was eliminated during the experiment by periodic calibration accomplished by substituting impulses of known duration from a crystal-controlled pulse generator having a stability of $0.001 \%$. At necropsy, appropriate positioning of all crystals was confirmed.

Regional myocardial blood flow was measured with isotopically labeled microspheres ( $15 \pm 2 \mu \mathrm{m}$ diam, New England Nuclear, Boston, MA) in six sham-operated dogs and in nine dogs in heart failure after 3 wk of rapid pacing. The radioactive label of the microspheres $\left({ }^{46} \mathrm{Sc}\right.$, ${ }^{51} \mathrm{Cr},{ }^{85} \mathrm{Sr},{ }^{95} \mathrm{Nb},{ }^{103} \mathrm{Ru},{ }^{113} \mathrm{Sn},{ }^{114} \mathrm{In}$, or ${ }^{141} \mathrm{Ce}$ ) was chosen randomly. The microspheres were suspended in $0.01 \%$ Tween 80 solution (10\% dextran) agitated by direct application of an ultrasonic probe to ensure dispersion of the microspheres and placed in an ultrasonic bath for at least $30 \mathrm{~min}$ before injection. Before injection of microspheres, $0.7 \mathrm{ml}$ of Tween 80 dextran solution (without microspheres) was injected to determine whether or not diluent for the microsphere suspension would have an adverse effect on measurement of cardiac or systemic hemodynamics. One to two million microspheres were injected through the catheter implanted in the left atrium for determination of blood flow. A reference sample of arterial blood was withdrawn (7.75 $\mathrm{ml} / \mathrm{min}$ ) from the catheter in the descending aorta. Reference sample withdrawal was initiated $15 \mathrm{~s}$ before microsphere injection and continued for $\sim 90 \mathrm{~s}$ after the injection was completed (total withdrawal time was $120 \mathrm{~s}$ ). After the animals were killed with a lethal dose of sodium pentobarbital $(50 \mathrm{mg} / \mathrm{kg})$ samples of myocardial tissue from the $\mathrm{LV}$ free walls were subdivided into four equal transmural layers from epicardium to endocardium, weighed, and placed in a gamma counter (Canberra Industries, Inc., Meriden, CT) with appropriately selected energy windows. The raw counts were corrected for background and crossover and compared with the reference blood sample to obtain flow expressed in milliliters per minute per gram of tissue. Transmural myocardial blood flow was determined as the average flow across all layers of the myocardium. Endocardial/epicardial blood flow ratios were obtained by dividing blood flow in the endocardial layer by the epicardial layer.

Model of pacing-induced cardiomyopathy. After completion of control studies, rapid right ventricular (RV) pacing was initiated at a rate of 240 beats/min, using a programmable miniature pacemaker (model EV4543, Pace Medical, Inc., Waltham, MA), worn externally in a vest. The dogs were examined daily to confirm the maintenance of pacing and to monitor for incipient signs of heart failure. During all experi- mental protocols, $\mathrm{RV}$ pacing was discontinued briefly so that hemodynamic measurements could be made during intrinsic sinus rhythm.

Protocol. 13 dogs were studied in the control state, 2-3 wk after instrumentation, when they were healthy and had completely recovered from the effects of surgery. The same 13 dogs were studied $23 \pm 2 \mathrm{~d}$ after initiation of rapid ventricular pacing when signs of clinical heart failure (exertional dyspnea, exercise intolerance, pulmonary edema, and ascites) were manifest. During both the control state and after the development of heart failure, measurements were made with the dogs fully awake, lying quietly on their right side after a 30-min stabilization period subsequent to deactivation of pacing. 12 of the same dogs were also studied to determine the sequence of development of impaired LV systolic and diastolic function $(3,5,7$, and $14 \mathrm{~d}$ after initiation of rapid ventricular pacing). Five of the same dogs were studied $24 \mathrm{~h}$ after pacing. To determine the role of altered loading conditions as determinants of the LV diastolic dysfunction, loading conditions were matched between the control and failure states in seven dogs by reducing the elevated LV end-systolic and diastolic wall stresses in the heart failure state by controlled hemorrhage $(30-50 \mathrm{ml} / \mathrm{min})$ and inferior vena caval occlusion, and increasing loading conditions by volume loading (50-80 ml/min) and aortic constriction in the control state. Heart rate was matched in the control and failure states using atrial pacing at 150 beats/min.

Data analysis. All data were recorded on a multichannel tape recorder (model 101, Honeywell, Inc., Denver, CO) and on a direct-writing oscillograph (Mark 200, Gould-Brush, Cleveland, $\mathrm{OH}$ ). The analog signals of LV pressure and dimension were digitized using a HP3852 on-line data acquisition and control unit (Hewlett-Packard Co., Palo Alto, CA), and stored in a HP9000 model 825 computer (HewlettPackard Co.) and were analyzed by the CROPA algorithm for digitizing LV function (19). Data were sampled at 2-ms intervals. The simultaneous LV pressure-dimension data for analysis were selected from beats averaged for $20 \mathrm{~s}$ over several respiratory cycles. Extrasystolic and postextrasystolic beats were excluded from the analysis.

The peak positive first derivative of $L V$ pressure $(\mathrm{d} P / \mathrm{d} t)$ served as the reference for beat detection. LV end-diastolic dimensions were measured at the beginning of the upstroke of $L V \mathrm{~d} P / \mathrm{d} t$. LV end-systolic dimensions were measured at the time of maximum negative $\mathrm{d} P / \mathrm{d} t$. Ejection time was taken as the interval between maximum and minimum LV d $P / \mathrm{d} t$. Duration of diastole was measured as the interval from the point of maximum negative $\mathrm{d} P / \mathrm{d} t$ to the beginning of the upstroke of $\mathrm{LV} \mathrm{d} P / \mathrm{d} t$. The isovolumic relaxation period was measured as the period from peak negative $\mathrm{d} P / \mathrm{d} t$ to $5 \mathrm{mmHg}$ above $\mathrm{LV}$ end-diastolic pressure (20).

Cavity volume (ml) was calculated using an ellipsoidal model (11), i.e.,

$\mathrm{EDV}=(\pi / 6)(\mathrm{EDD})^{2}(\mathrm{EDL}-0.55 \times \mathrm{EDW}) / 1,000$

and

$\mathrm{ESV}=(\pi / 6)(\mathrm{ESD})^{2}(\mathrm{ESL}-0.55 \times \mathrm{ESW}) / 1,000$

where EDV is LV end-diastolic volume, ESV is LV end-systolic volume, EDD is LV endocardial end-diastolic short axis ( $\mathrm{mm}$ ), ESD is LV endocardial end-systolic short axis $(\mathrm{mm}), E D L$ is $L V$ end-diastolic long axis ( $\mathrm{mm})$, ESL is LV end-systolic long axis ( $\mathrm{mm})$, EDW is end-diastolic wall thickness ( $\mathrm{mm}$ ), and ESW is end-systolic wall thickness ( $\mathrm{mm}$ ). Notice that a wall thickness factor $(0.55 \times$ EDW or ESW) was subtracted from the measured long axis because one of the long-axis crystals was endocardial and the second was epicardial $(11,13)$. LV wall volume $\left(V_{w}\right)$ was calculated as the difference between $L V$ external diastolic ventricular volume (EVV) and EDV. EVV was defined as:

$\mathrm{EVV}=(\pi / 6)(\mathrm{EDD}+2 \times \mathrm{EDW})^{2}(\mathrm{EDL}+0.45 \times \mathrm{EDW}) / 1,000$

LV ejection fraction (EF) was calculated similarly using:

$\mathrm{EF}(\%)=(\mathrm{SV} / \mathrm{EDV}) \times 100 \%$ 

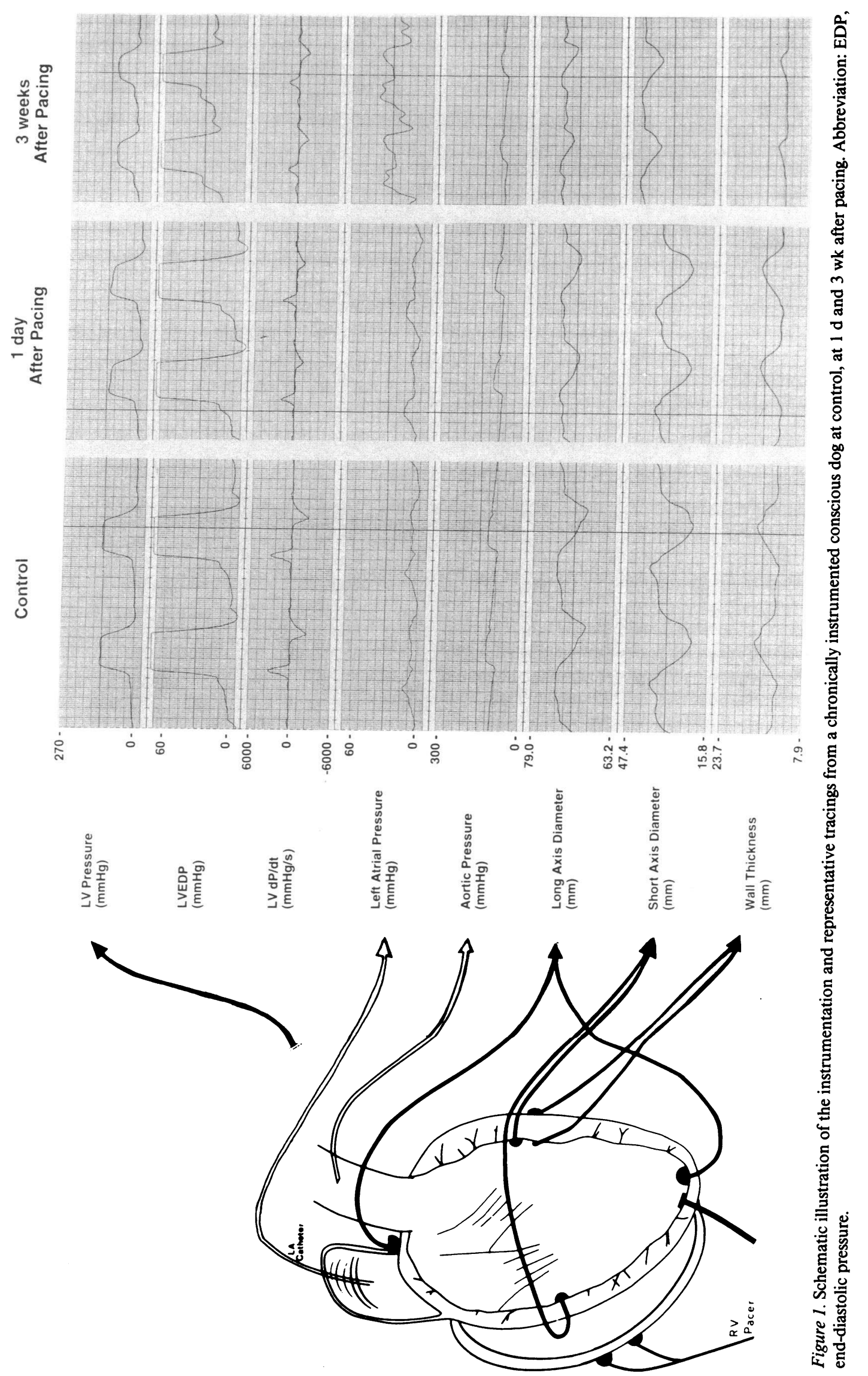
where SV (stroke volume) = EDV - ESV. The mean velocity of circumferential fiber shortening ( $\mathrm{Vcf}, \mathrm{s}^{-1}$ ) was calculated as follows:

$\mathrm{Vcf}=(\mathrm{EDD}-\mathrm{ESD}) /(\mathrm{EDD} \times \mathrm{ET})$

where ET is ejection time in seconds.

Tension-time index (mean aortic systolic pressure multiplied by ejection time multiplied by heart rate) and triple product (LV systolic pressure multiplied by $\mathrm{LV} \mathrm{d} P / \mathrm{d} t$ multiplied by heart rate) were calculated as indexes of myocardial oxygen consumption. LV circumferential wall stress $(\sigma)$ was calculated at end-systole and end-diastole assuming an ellipsoidal model $(11,21)$ as:

$$
\begin{aligned}
& \sigma_{\mathrm{ed}}=(1.36 \times \mathrm{LVEDP} \times \mathrm{EDD} \times \mathrm{EDL}) /(2 \times \mathrm{EDW}) \\
& \times(\mathrm{EDL}+0.55 \times \mathrm{EDD}+1.1 \times \mathrm{EDW}) \\
& \sigma_{\mathrm{es}}=(1.36 \times \mathrm{LVESP} \times \mathrm{ESD} \times \mathrm{ESL}) /(2 \times \mathrm{ESW}) \\
& \times(\mathrm{ESL}+0.55 \times \mathrm{ESD}+1.1 \times \mathrm{ESW})
\end{aligned}
$$

where LVEDP and LVESP are the LV end-diastolic and the LV endsystolic pressures, respectively.

The time constant of isovolumic LV pressure decay $(\tau)$ was calculated using pressure data from peak negative $\mathrm{d} P / \mathrm{d} t$ to a pressure equal to $\mathrm{LV}$ end-diastolic pressure $+5 \mathrm{mmHg}$. Tau was calculated by three methods. The first method (22) assumes that LV pressure falls monoexponentially toward zero during isovolumic relaxation so that

$\mathrm{LVP}=P_{0} e^{-t / T_{\mathrm{L}}}$

where LVP is the LV intracavitary pressure calibrated to atmospheric zero using the pressure reference from the LV catheter, $P_{0}$ is LV pressure at the start of decay, $t$ is time, and $T_{\mathrm{L}}$ is the time constant of isovolumic relaxation. The second method (23) assumes a variable asymptote for LV pressure decay, taking into account the effects of extramural forces (pleural pressure, interventricular dependence, or baseline shift). Thus,

$\mathrm{LVP}=\left(P_{0}-P_{\mathrm{B}}\right) e^{-t / T_{\mathrm{D}}}+P_{\mathrm{B}}$

where, in addition to the symbols described previously, $P_{\mathrm{B}}$ is the pressure to which LV pressure would decay given infinite time, and $T_{\mathrm{D}}$ is the time constant of isovolumic relaxation using this method. The third model calculated directly the three parameters $\left(P_{0}, P_{\mathrm{B}}, \tau\right)$ by nonlinear least-squares fit using the Marquardt gradient expansion algorithm (24). In practice, starting points used in the iterative procedure were those obtained by the second method. We denoted the time constant from the third method as $T_{\mathrm{N}}$.

The radial myocardial stiffness constant was calculated from minimum $\mathrm{LV}$ pressure to the peak of atrial contraction using the formula of Mirsky (25), previously used in this laboratory (16-18):

$\mathbf{L V P}=B h^{-\beta}$

where $h$ is the wall thickness and $\beta$ is the radial myocardial stiffness constant. Occasionally, especially in the control states with atrial pacing, the LV pressure during diastole reached negative values even if intrathoracic pressure was taken into account. In that case, the equation for myocardial stiffness could not be solved. Therefore, we calculated myocardial stiffness using the equation with a constant, i.e., LVP $=B h^{-\beta}+D$, where $D$ is a pressure constant for curve fitting. We also calculated stiffness without the added pressure constant. The results were qualitatively similar using both calculations. To calculate operating chamber stiffness, simultaneous paired pressure-volume data were derived from the diastolic portion of a single beat under steady-state conditions and were fitted to the monoexponential curve:

$\mathbf{L V P}=A e^{\alpha \mathbf{V}}+C$

where $\alpha$ is a chamber stiffness coefficient (26), $A$ is a curve-fitting constant, and $C$ is the pressure intercept. For the purpose of comparison, $\alpha$ was normalized to LV wall volume $\left(\alpha_{\mathrm{n}}\right)$. The chamber stiffness constant, $k$, and a normalized $k\left(k_{\mathrm{n}}\right)$ were calculated from the LV end-dia- stolic chamber stiffness vs. pressure data during hemorrhage and volume load.

Pathology. After completion of the experimental protocol, both sham operated controls and dogs with heart failure were euthanized with a lethal dose of sodium pentobarbital $(50 \mathrm{mg} / \mathrm{kg})$. Five of the paced dogs and all of the control dogs were perfusion fixed in situ through an aortic cannula with $2 \%$ phosphate-buffered glutaraldehyde as previously described (18). The additional paced dog hearts were immersion fixed in 10\% phosphate-buffered formaldehyde. The hearts were excised and trimmed of excess tissue. The atria were removed and the right ventricle was separated from the left ventricle. The right ventricle and left ventricle plus septum were then weighed separately. Because the body weight of heart failure dogs was altered due to ascites, the ratio of heart weight to body weight was calculated using presurgery body weight values.

Histologic studies were conducted on hearts from seven sham dogs and eight of the heart failure dogs. Transmural sections of myocardium in both horizontal and vertical planes were taken from the interventricular septum, $L V$ posterior wall, $L V$ anterior wall, $L V$ free wall, and $R V$ free wall $($ total $=10)$. Care was taken to avoid areas adjacent to implanted instrumentation. Tissues were embedded in paraffin and 5- $\mu \mathrm{m}$ sections were stained with hematoxylin and eosin, Gomori's aldehyde fuchsin trichrome, and picrosirius red. The stained sections were divided into two adjacent transmural layers, i.e., epi- and endomyocardial layers. One section from each of the three $L V$ regions was analyzed quantitatively for determination of the type and amount of connective tissue present (27). The quantitative approach used a video imaging system (Image Technology, Deer Park, NY) in which a microscope with video camera is interfaced to an IBM model 80286 computer with software programmed to calculate the percentage of pixels exceeding a selected density. Picrosirius red-stained sections were examined with a green filter to provide maximal monochromatic contrast on the video system between the red-stained connective tissue and the yellowstained muscle tissue on the 256 gray scale. A minimum of 30 fields were measured in both the epi- and endomyocardial layers in each slide. Fields were measured by use of the $\times 10$ objective with the limiting screen on the video set for a $600 \times 600 \mu \mathrm{m}^{2}$ area. Adjacent fields were measured following an alternating inner-to-outer, outer-to-inner pattern through each region, excluding fields with technical artifacts or large ( $>150 \mu \mathrm{m}$ in diameter) vascular spaces. Perivascular tissue was included. Mean volume percent of connective tissue for each epi- or endomyocardial region was calculated from the three slides and these values were combined for determination of group means. Hydroxyproline was determined on three subendo- and three subepimyocardial regions of fixed tissue in each dog; tissue values were combined to obtain regional mean values. Care was taken to avoid the endo- and epicardium or regions adjacent to instrumentation. Hydroxyproline content was measured spectrophotometrically by the method of Woessner $(18,28)$. Results were expressed as micrograms hydroxyproline per milligram dry weight of sample.

Statistics (29). Data are expressed as mean \pm standard error. Differences between the dogs studied at control and at day 1 , and between control and 3 wk after rapid pacing were compared by Student's $t$ test for paired comparison, with differences considered significant at a level of $P<0.05$. The Student's $t$ test for unpaired comparison was used for comparison of variables between sham dogs and heart failure dogs.

\section{Results}

Serial changes in LV and systemic hemodynamics. Paired analyses are shown at $1 \mathrm{~d}$ (Table I) and 3 wk (Table II) of rapid ventricular pacing for the same dogs studied at these intervals compared with their respective control values. Mean arterial pressure at $1 \mathrm{~d}$ was unchanged from control but was reduced by $9 \pm 3 \mathrm{mmHg}(P<0.001)$ at $3 \mathrm{wk}$ after pacing. Heart rate was unchanged at $1 \mathrm{~d}$ but was elevated by $21 \pm 6$ beats/min $(P$ 
Table I. LV and Systemic Hemodynamics in the Same Five Dogs Studied in the Control State and 1 d after Rapid Ventricular Pacing

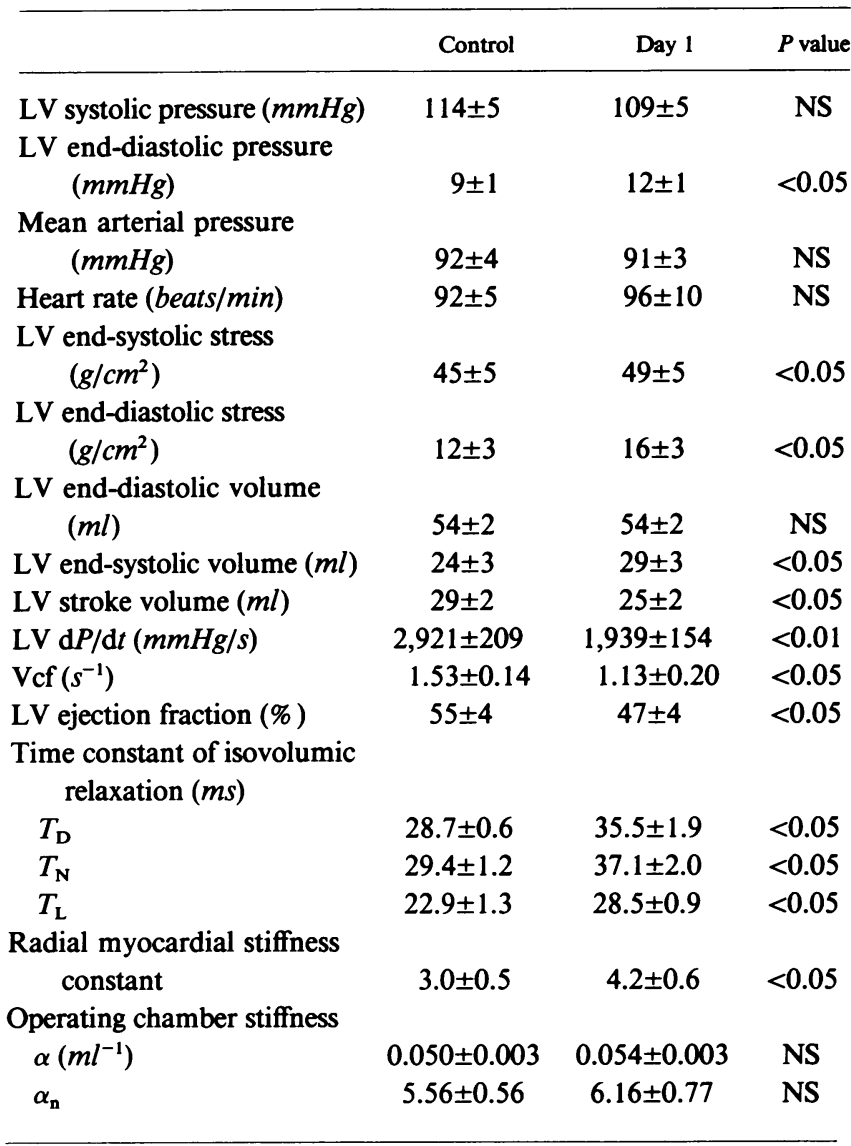

Values are mean $\pm \mathrm{SEM}$. Abbreviations: $T_{\mathrm{L}}$, time constant of isovolumic relaxation obtained by the semilogarithmic method with zero asymptote; $T_{\mathrm{D}}$, time constant of isovolumic relaxation obtained by the derivative method with nonzero asymptote; $T_{\mathrm{N}}$, time constant of isovolumic relaxation obtained by the nonlinear least-squares fitting with nonzero asymptote; $\alpha$, coefficient of chamber stiffness obtained by fit to steady-state data; $\alpha_{\mathrm{n}}$, normalized $\alpha$ to $\mathrm{LV}$ wall volume.

$<0.001$ ) after 3 wk of pacing. LV systolic pressure was unchanged from control at $1 \mathrm{~d}$ but was reduced by $17 \pm 3 \mathrm{mmHg}$ $(P<0.001)$ after $3 \mathrm{wk}$ of pacing. LV end-diastolic pressure at 1 d was increased by $3 \pm 1 \mathrm{mmHg}(P<0.05)$ and was elevated by $20 \pm 2 \mathrm{mmHg}(P<0.001)$ after 3 wk of pacing.

Serial changes in LV end-diastolic and end-systolic stresses and volumes are shown in Fig. 2. LV end-systolic stress was increased at $1 \mathrm{~d}$ by $4 \pm 1 \mathrm{~g} / \mathrm{cm}^{2}(P<0.05)$ and was elevated by $29 \pm 6 \mathrm{~g} / \mathrm{cm}^{2}(P<0.001)$ after $3 \mathrm{wk}$ of pacing. LV end-diastolic stress was increased at $1 \mathrm{~d}$ by $4 \pm 1 \mathrm{~g} / \mathrm{cm}^{2}(P<0.05)$ and was elevated by $40 \pm 5 \mathrm{~g} / \mathrm{cm}^{2}(P<0.001)$ after 3 wk of pacing. $\mathrm{LV}$ end-diastolic volume was unchanged from control at $1 \mathrm{~d}$ but was significantly elevated by $23 \pm 2 \mathrm{ml}(P<0.001)$ after 3 wk of pacing. LV end-systolic volume was increased at $1 \mathrm{~d}$ by $5 \pm 2 \mathrm{ml}$ $(P<0.05)$ and was significantly elevated by $28 \pm 2 \mathrm{ml}(P$ $<0.001)$ after 3 wk of pacing. LV stroke volume was decreased at $1 \mathrm{~d}$ by $5 \pm 2 \mathrm{ml}(P<0.05)$ and was reduced by $6 \pm 1 \mathrm{ml}(P$ $<0.002$ ) after 3 wk of pacing.

Table III reveals the average transmural myocardial blood flow and endocardial/epicardial blood flow ratio in six sham-
Table II. LV and Systemic Hemodynamics in the Same 13 Dogs Studied in the Control State and 3 wk after Rapid Ventricular Pacing (Heart Failure)

\begin{tabular}{lccc}
\hline & Control & $\begin{array}{c}\text { Heart } \\
\text { failure }\end{array}$ & $P$ value \\
\hline $\begin{array}{l}\text { LV systolic pressure } \\
\quad(m m H g)\end{array}$ & $119 \pm 3$ & $102 \pm 2$ & $<0.001$ \\
$\begin{array}{l}\text { LV end-diastolic pressure } \\
\quad(m m H g)\end{array}$ & $8 \pm 1$ & $28 \pm 2$ & $<0.001$ \\
$\begin{array}{l}\text { Mean arterial pressure } \\
\quad(m m H g)\end{array}$ & $96 \pm 3$ & $87 \pm 3$ & $<0.001$ \\
Heart rate $($ beats $/$ min) & $96 \pm 5$ & $117 \pm 6$ & $<0.001$ \\
LV end-systolic stress & & & \\
$\quad\left(g / \mathrm{cm}^{2}\right)$ & $58 \pm 3$ & $87 \pm 4$ & $<0.001$ \\
LV end-diastolic stress & & & \\
$\quad\left(g / \mathrm{cm}^{2}\right)$ & $12 \pm 1$ & $53 \pm 6$ & $<0.001$ \\
LV end-diastolic volume & & & \\
$\quad(m l)$ & $56 \pm 2$ & $79 \pm 3$ & $<0.001$ \\
LV end-systolic volume & & & \\
$\quad(m l)$ & $28 \pm 2$ & $56 \pm 2$ & $<0.001$ \\
LV stroke volume $(m l)$ & $28 \pm 2$ & $22 \pm 2$ & $<0.002$ \\
LV dP/dt $(m m H g / s)$ & $2,865 \pm 155$ & $1,539 \pm 103$ & $<0.001$ \\
Vcf $\left(s^{-1}\right)$ & $1.34 \pm 0.09$ & $0.79 \pm 0.08$ & $<0.001$ \\
LV ejection fraction $(\%)$ & $50 \pm 3$ & $28 \pm 2$ & $<0.001$ \\
LV wall volume $(m l)$ & $114 \pm 4$ & $119 \pm 6$ & $\mathrm{NS}$ \\
& & & \\
\hline
\end{tabular}

Values are mean \pm SEM

operated controls and nine of the dogs studied after 3 wk of pacing. The average transmural flow was reduced in heart failure in keeping with reduced determinants of myocardial demand as reflected by the reduced tension-time index and triple product (Table III). Although average transmural flow was less in heart failure, there was no evidence of subendocardial hypoperfusion at baseline as reflected by the normal endo/epi ratio.
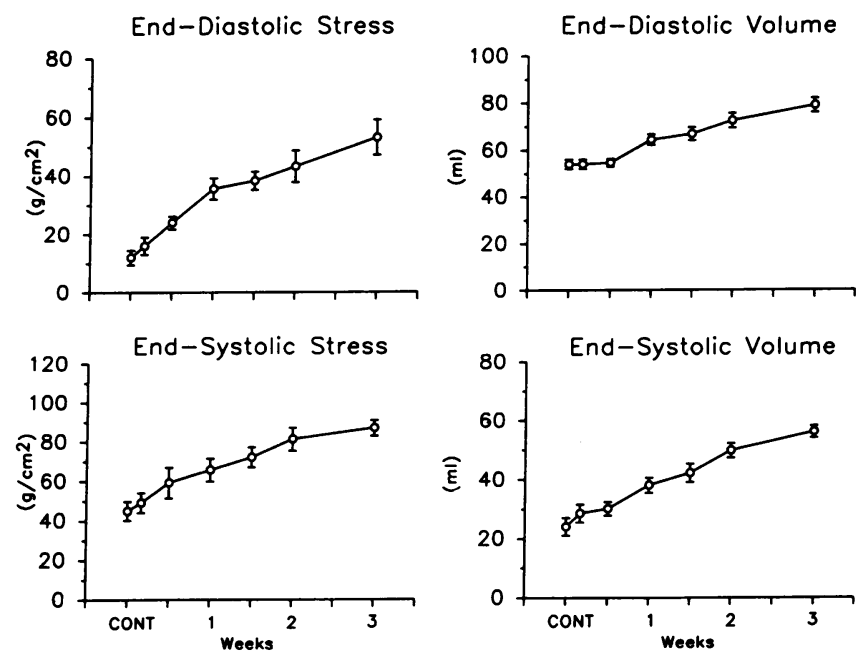

Figure 2. The sequential changes in systolic and diastolic LV wall stresses and volumes are shown at control, at $1 \mathrm{~d}$, and at selected intervals after initiating rapid pacing. Both LV end-diastolic and end-systolic wall stresses were increased at $1 \mathrm{~d}$ after initiation of rapid ventricular pacing and continued to be increased progressively over the 3-wk monitoring period, as did LV end-diastolic and end-systolic volumes. 
Table III. Myocardial Blood Flow and Triple Product

\begin{tabular}{lccc}
\hline & $\begin{array}{c}\text { Sham dogs } \\
(n=6)\end{array}$ & $\begin{array}{c}\text { Heart failure } \\
\text { dogs } \\
(n=9)\end{array}$ & $\begin{array}{c}P \\
\text { value }\end{array}$ \\
\hline $\begin{array}{c}\text { Transmural coronary blood } \\
\text { flow }(\mathrm{ml} / \text { min per } \text { g) }\end{array}$ & $1.02 \pm 0.10$ & $0.72 \pm 0.05$ & $<0.05$ \\
$\begin{array}{c}\text { Endocardial/epicardial flow } \\
\text { ratio }\end{array}$ & $1.31 \pm 0.08$ & $1.12 \pm 0.09$ & NS \\
$\begin{array}{c}\text { Tension-time index } \\
(m m H g \cdot s / m i n)\end{array}$ & $2027 \pm 60$ & $1,724 \pm 86$ & $<0.05$ \\
$\begin{array}{c}\text { Triple product }\left(\times 10^{6}\right. \\
\left.m m H g^{2} \cdot \text { beat } / s^{2}\right)\end{array}$ & $2,554 \pm 182$ & $1,015 \pm 110$ & $<0.001$ \\
\hline
\end{tabular}

Values are mean \pm SEM.

Serial changes in indexes of $L V$ systolic function. Paired analyses are shown at $1 \mathrm{~d}$ (Table I) and $3 \mathrm{wk}$ (Table II) of rapid ventricular pacing for the same dogs studied at these intervals compared with their respective control values. Serial changes are depicted in Fig. 3. $\mathrm{LV} \mathrm{d} P / \mathrm{d} t$ was decreased from control within $1 \mathrm{~d}$ by $982 \pm 166 \mathrm{mmHg} / \mathrm{s}(P<0.01)$ and was significantly reduced by $1,327 \pm 105 \mathrm{mmHg} / \mathrm{s}(P<0.001)$ after $3 \mathrm{wk}$ of pacing. LV Vcf was decreased by $0.40 \pm 0.11 \mathrm{~s}^{-1}(P<0.05)$ at $1 \mathrm{~d}$ and was significantly reduced by $0.54 \pm 0.10 \mathrm{~s}^{-1}(P<0.001)$ after 3 wk of pacing. Ejection fraction was decreased by $9 \pm 2$ percentage units $(P<0.05)$ at $1 \mathrm{~d}$ and was significantly reduced by $22 \pm 2$ percentage units $(P<0.001)$ after 3 wk of pacing.

Serial changes in indexes of $L V$ diastolic function. Paired analyses are shown at $1 \mathrm{~d}$ (Table I) and after $3 \mathrm{wk}$ (Table IV) of rapid ventricular pacing for the same dogs studied at these intervals compared with their respective control values. Serial changes are depicted in Fig. 4. $T_{\mathrm{D}}$ was increased significantly by $6.8 \pm 1.7 \mathrm{~ms}(P<0.05)$ (Table I) at $1 \mathrm{~d}$ and was elevated by $14.0 \pm 2.8 \mathrm{~ms}(P<0.001)$ after 3 wk of pacing (Table IV, Fig. 4). $T_{\mathrm{N}}$ and $T_{\mathrm{L}}$ yielded changes similar to those obtained from $T_{\mathrm{D}}$ (Tables I and IV). The duration of diastole was significantly shortened in the heart failure state by $90.7 \pm 27.0 \mathrm{~ms}(P<0.01)$ from control as was the isovolumic relaxation period by $12.8 \pm 2.2 \mathrm{~ms}(P<0.001)$ (Table IV).

The myocardial stiffness constant was increased significantly by $1.2 \pm 0.3(P<0.05)$ (Table I) at $1 \mathrm{~d}$ and was elevated further to $9.5 \pm 1.5(P<0.002)$ after 3 wk of pacing. However, chamber stiffness, $\alpha_{n}$, was not changed significantly over the 3-wk period of study (Table IV, Fig. 4).

Fig. 5 illustrates a representative LV end-diastolic pressurevolume relationship for an animal studied at control and after 3 wk of rapid ventricular pacing. Although the relationship was shifted to the right in heart failure, there was no difference in the modulus of chamber stiffness suggesting no significant change in LV diastolic chamber compliance.

Table IV includes the values for ventricular chamber stiffness in the control and heart failure states. There were no significant differences in the indices of chamber stiffness assessed from chamber stiffness vs. pressure data, whether data were derived from $\mathrm{LV}$ end-diastolic pressure-volume relation during hemorrhage and volume load (control $k=0.14 \pm 0.04 \mathrm{ml}^{-1}, k_{\mathrm{n}}$ $=18.7 \pm 4.0$; heart failure $k=0.14 \pm 0.02 \mathrm{ml}^{-1}, k_{\mathrm{n}}=14.4 \pm 1.9$ ) or from steady-state cardiac cycles (control $\alpha=0.048 \pm 0.002$ $\mathrm{ml}^{-1}, \alpha_{\mathrm{n}}=5.50 \pm 0.30$; heart failure $0.048 \pm 0.002 \mathrm{ml}^{-1}, \alpha_{\mathrm{n}}$ $=5.75 \pm 0.45$ ).

Load dependence of $L V$ systolic and diastolic function. The effects of increases in preload and afterload at constant heart rate were examined on LV systolic and diastolic function in seven control dogs. When LV end-diastolic and end-systolic stresses were increased significantly by $30.7 \pm 5.2 \mathrm{~g} / \mathrm{cm}^{2}(P$ $<0.005)$ and $48.1 \pm 16.0 \mathrm{~g} / \mathrm{cm}^{2}(P<0.05)$, respectively, in the control state, $T_{\mathrm{D}}$ was increased by $7.7 \pm 3.1 \mathrm{~ms}(P<0.05)$ as was the myocardial stiffness constant, by $1.0 \pm 0.3(P<0.05) . T_{\mathrm{N}}$ and $T_{\mathrm{L}}$ yielded similar changes $(P<0.05)$. However, chamber stiffness remained unchanged. Insignificant increases in LV $\mathrm{d} P / \mathrm{d} t(+321 \pm 257 \mathrm{mmHg} / \mathrm{s})$ and insignificant decreases in $\mathrm{Vcf}$ $\left(-0.14 \pm 0.15 \mathrm{~s}^{-1}\right)$ and $\mathrm{LV}$ ejection fraction $(-2.6 \pm 5.4 \%)$ were also observed.

$L V$ systolic and diastolic function with matched loading conditions. The effects of increases in preload and afterload at constant heart rate in the control state to match levels attained in the heart failure state are shown on indexes of LV systolic and diastolic function in Figs. 6 and 7, respectively. Although the marked differences in LV systolic contractile parameters between the control and heart failure states persisted with matched loading conditions (Fig. 6), the indexes of LV diastolic function were no longer different in the heart failure state when loading conditions were matched in the control state (Fig. 7).
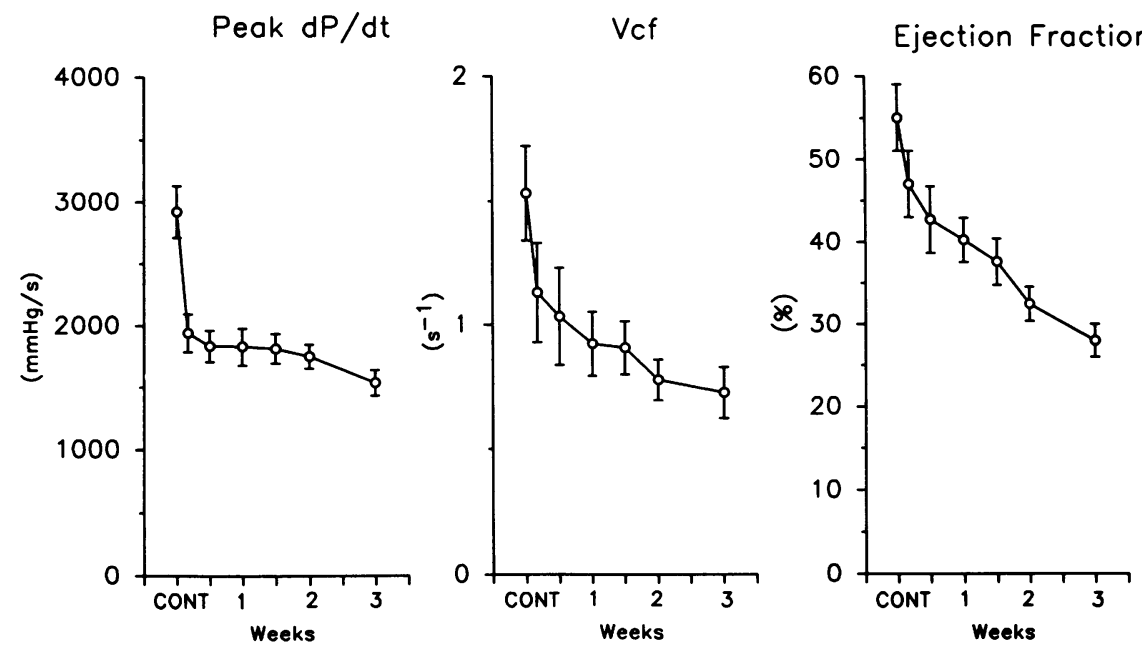

Figure 3. The time course of the changes in LV $\mathrm{d} P / \mathrm{d} t$, mean velocity of circumferential fiber shortening (Vcf), and ejection fraction. LV $\mathrm{d} P / \mathrm{d} t, \mathrm{Vcf}$, and ejection fraction were decreased within $1 \mathrm{~d}$ after initiation of rapid pacing and continued to be declined gradually over the remainder of the 3-wk monitoring period. 
Table IV. Changes in LV Diastolic Function in the Same 13 Dogs Studied in the Control State and after 3 wk of Ventricular Pacing (Heart Failure)

\begin{tabular}{|c|c|c|c|}
\hline & Control & $\begin{array}{l}\text { Heart } \\
\text { failure }\end{array}$ & $\begin{array}{c}P \\
\text { value }\end{array}$ \\
\hline \multicolumn{4}{|l|}{$\begin{array}{l}\text { Time constant of } \\
\text { isovolumic relaxation } \\
(m s)(n=13)\end{array}$} \\
\hline$T_{\mathrm{D}}$ & $29.7 \pm 0.7$ & $44.0 \pm 3.1$ & $<0.00$ \\
\hline$T_{\mathrm{N}}$ & $31.7 \pm 1.1$ & $47.4 \pm 3.8$ & $<0.002$ \\
\hline$T_{\mathrm{L}}$ & $23.5 \pm 0.8$ & $38.6 \pm 2.2$ & $<0.001$ \\
\hline \multicolumn{4}{|l|}{ Radial myocardial stiffness } \\
\hline constant $(n=13)$ & $3.1 \pm 0.3$ & $9.5 \pm 1.5$ & $<0.002$ \\
\hline \multicolumn{4}{|l|}{$\begin{array}{l}\text { Chamber stiffness } \\
\quad \text { coefficient }(n=13)\end{array}$} \\
\hline$\alpha\left(m l^{-1}\right)$ & $0.048 \pm 0.002$ & $0.048 \pm 0.002$ & NS \\
\hline$\alpha_{n}$ & $5.50 \pm 0.30$ & $5.75 \pm 0.45$ & NS \\
\hline \multicolumn{4}{|l|}{$\begin{array}{l}\text { Chamber stiffness constant } \\
\qquad(n=7)\end{array}$} \\
\hline$k\left(m l^{-1}\right)$ & $0.14 \pm 0.04$ & $0.14 \pm 0.02$ & NS \\
\hline$k_{\mathrm{n}}$ & $18.7 \pm 4.0$ & $14.4 \pm 1.9$ & NS \\
\hline \multicolumn{4}{|l|}{ Duration of diastole $(\mathrm{ms})$} \\
\hline$(n=13)$ & $404 \pm 25$ & $313 \pm 25$ & $<0.01$ \\
\hline $\begin{array}{l}\text { Isovolumic relaxation } \\
\quad \text { period }(m s)(n=13)\end{array}$ & $38.9 \pm 1.3$ & $26.0 \pm 2.3$ & $<0.001$ \\
\hline
\end{tabular}

Values are mean \pm SEM. Abbreviations: $k$, chamber stiffness constant obtained by fit to end-diastolic chamber stiffness vs. pressure during hemorrhage and volume load; $k_{\mathrm{n}}$, normalized $k$ to $\mathrm{LV}$ wall volume. Other abbreviations as in Table $\mathrm{I}$.

The effects of reducing LV preload and afterload in the heart failure state to match levels observed in the control state are shown on indexes of LV systolic and diastolic function in Figs. 8 and 9, respectively. Whereas the indexes of LV systolic function remained depressed (Fig. 8), the indexes of LV diastolic function were no longer different when loading conditions were matched in the failure state (Fig. 9).

Pathology. There were no significant differences in body weights between sham-operated controls and dogs with heart failure (Table V). There were no significant increases in LV plus septum weight/body weight in dogs with heart failure $(5.2 \pm 0.3 \mathrm{~g} / \mathrm{kg})$ compared with sham-operated controls $(5.0 \pm 0.1 \mathrm{~g} / \mathrm{kg})$. There were also no differences in $\mathrm{RV}$ weight/ body weight in dogs with heart failure $(1.9 \pm 0.1 \mathrm{~g} / \mathrm{kg})$ compared with sham-operated controls $(1.8 \pm 0.1 \mathrm{~g} / \mathrm{kg})$. Thus, there appeared to be no significant increase in ventricular mass observed in this model of heart failure over the 3-wk period of rapid ventricular pacing.

Light microscopic histopathologic evaluation of the sections of the $\mathrm{LV}$ revealed no differences between the dogs with heart failure and sham-operated controls. Quantitative analysis of connective tissue by measurement of hydroxyproline concentration revealed no differences in transmural, epi- and endomyocardial layers between the dogs with heart failure (epi 9.8 \pm 0.9 ; endo $8.5 \pm 1.8$; transmural $8.2 \pm 0.6 \mu \mathrm{g} / \mathrm{mg}$ ) and shamoperated controls (epi 7.6 \pm 0.9 ; endo 9.7 \pm 1.9 ; transmural $8.1 \pm 0.6 \mu \mathrm{g} / \mathrm{mg}$ ) (Fig. 10). Quantitative evaluation of connective tissue by video imaging analysis also revealed no differences in transmural, epi- and endomyocardial layers between the dogs with heart failure (epi 3.1 \pm 0.3 ; endo $2.5 \pm 0.3$; transmural $2.8 \pm 0.3 \%$ ) and sham-operated controls (epi 3.7 \pm 0.7 ; endo $2.7 \pm 0.4$; transmural $3.2 \pm 0.5 \%$ ) (Fig. 10). To evaluate the possibility that small focal regions of myocardial connective tissue increase may have been present, we plotted the combined data as a histogram of the number of fields in the control and paced groups over the range of connective tissue content per field (Fig. 11). A total of 2026 fields were measured in seven control dogs and 2,509 fields in eight heart failure dogs. These data indicate that there was no difference in connective tissue distribution as measured by the picrosirius red technique at the light microscopic level. Thus, there were no quantitative changes in myocardial connective tissue at this stage of the heart failure process.

\section{Discussion}

In the present investigation conducted in conscious dogs, pacing-induced heart failure was characterized by marked LV systolic and diastolic dysfunction. The indices employed encompassed both active and passive aspects of diastole and were consistent with abnormalities which have been described in the advanced stages of human dilated cardiomyopathy (30-34). In
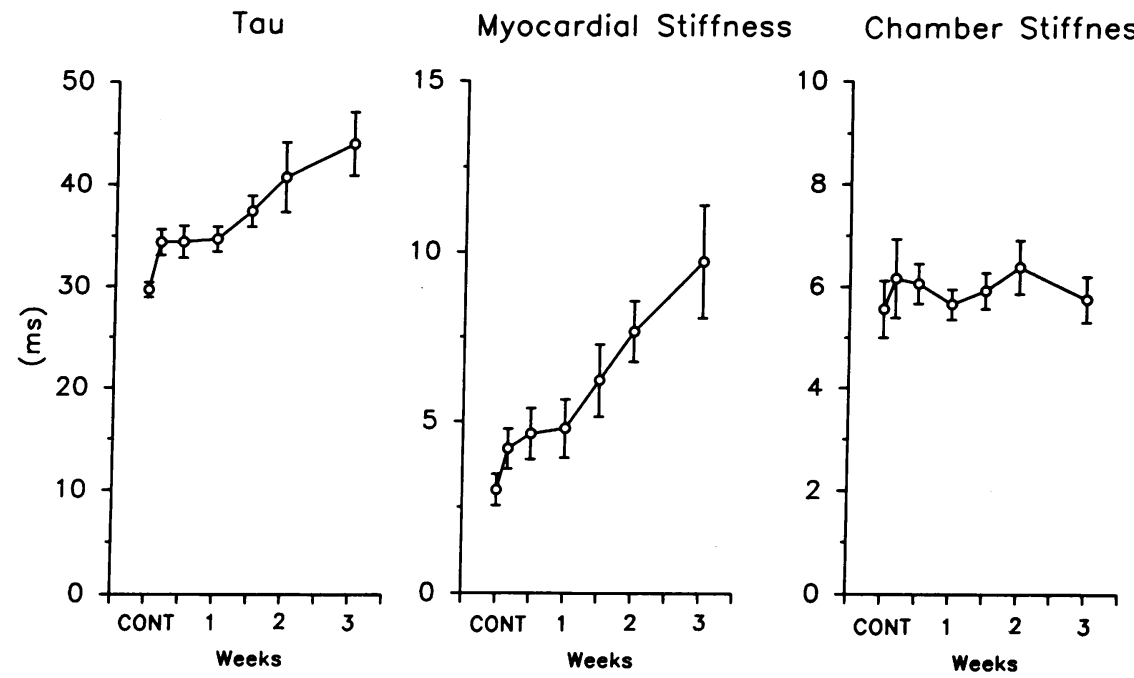

Figure 4. The time course of the changes in the isovolumic relaxation time constant obtained by the derivative method with nonzero asymptote $\left(T_{\mathrm{D}}\right)$, myocardial stiffness, and the coefficient of chamber stiffness normalized to LV wall volume $\left(\alpha_{n}\right)$. Isovolumic relaxation time constant and myocardial stiffness were increased at $1 \mathrm{~d}$ after initiation of rapid ventricular pacing and continued to be increased further over the 3-wk monitoring period, whereas chamber stiffness remained unchanged over the period of the study. 


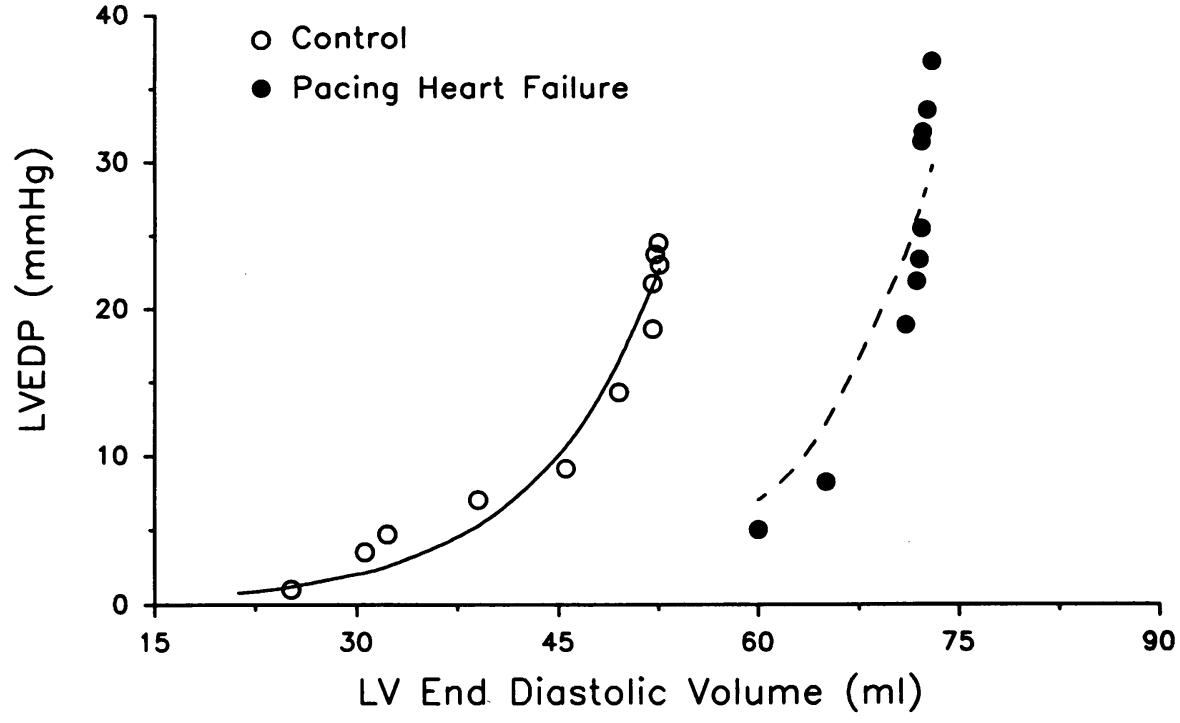

Figure 5. LV end-diastolic pressure-volume relationship during hemorrhage and volume load before (o) and after ( $\bullet$ ) development of heart failure. The pressure-volume curve was shifted to the right in the failure state, but the slope was unaltered. addition, we observed that the LV diastolic abnormalities develop in close temporal relationship with the LV systolic abnormalities and were evident within $24 \mathrm{~h}$ of initiating the insult of RV pacing. The abnormalities in LV diastolic and systolic function progressed over the course of the 3-wk study period. Most importantly, while the abnormalities in LV systolic function were relatively independent of load, the abnormalities in LV diastolic function appeared to be due in major part to the alterations in LV end-systolic and end-diastolic wall stresses observed in this model of heart failure, and can be reversed by normalizing the loading conditions on the heart. The lack of any increase in collagen through this stage of the heart failure process was consistent with a load-dependent and a reversible mechanism for the LV diastolic dysfunction.

Abnormalities in $\mathrm{LV}$ diastolic function are characteristic of heart failure $(1,2)$ in both patients $(30-36)$ and in experimental models $(12,17,37)$. Prior studies have suggested that alterations in LV diastolic function in heart failure are due to intrinsic properties of the cardiac myocytes (38) or to intracellular calcium regulation (39-41), concomitant myocardial ischemia $(17)$, or alterations in collagen content $(42,43)$. In that it is well recognized that many of the indexes of diastolic function are

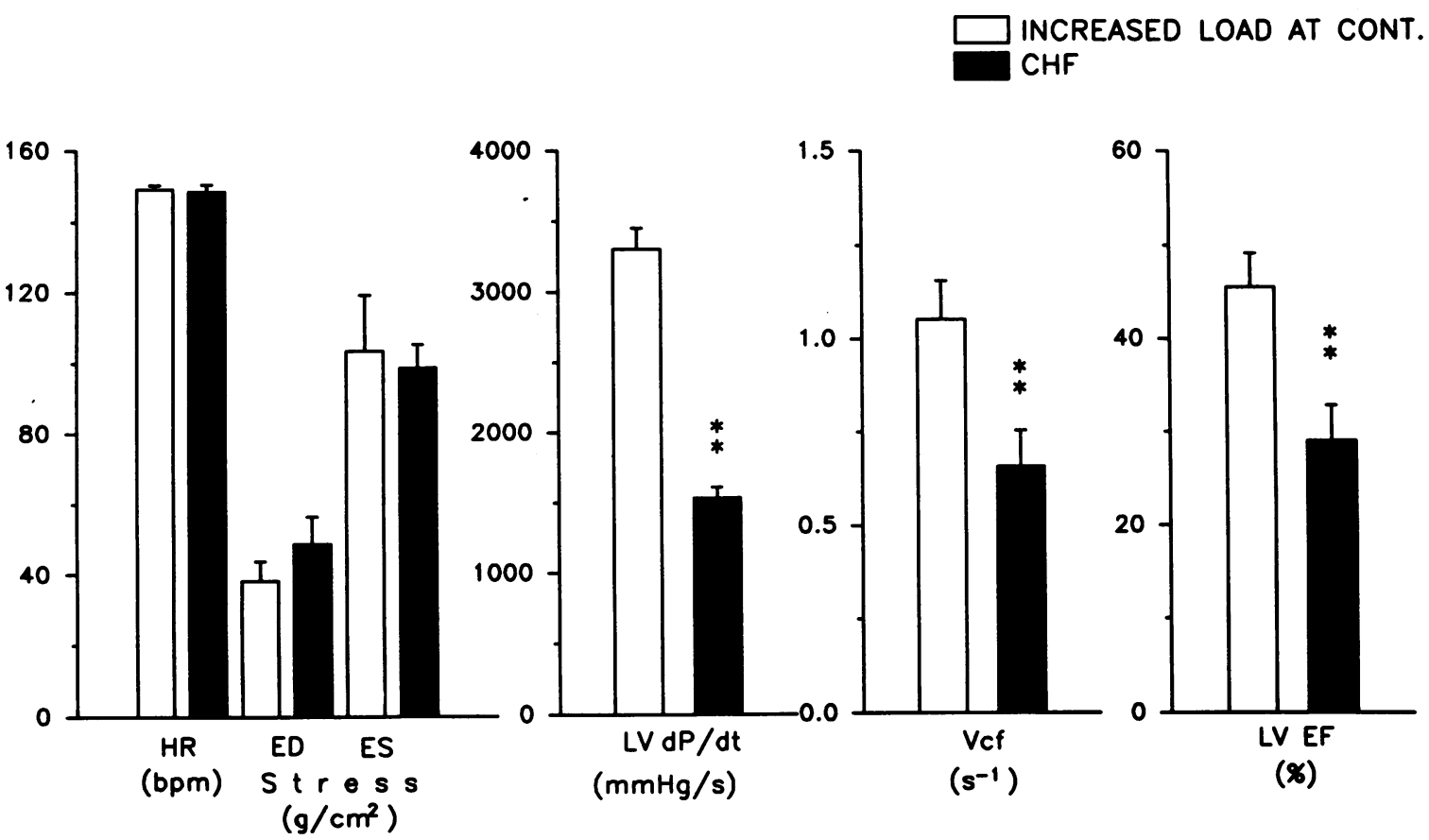

Figure 6. Changes in LV systolic function ( $\mathrm{LV} \mathrm{d} P / \mathrm{d} t, \mathrm{LV}$ mean velocity of circumferential fiber shortening [Vcf], and ejection fraction $\mathrm{LV}$ [EF]) compared before and $3 \mathrm{wk}$ after rapid ventricular pacing. Values in the control state with elevated loading conditions to match those attained in heart failure were used for comparison. Heart rates at both the control and failure states were matched by left atrial pacing ( 150 beats/min). Even with matched LV end-diastolic and end-systolic stresses, LV systolic function was depressed significantly in failure. Abbreviations: HR, heart rate; ED, end-diastolic; ES, end-systolic. ${ }^{* *} P<0.01$ vs. control. 

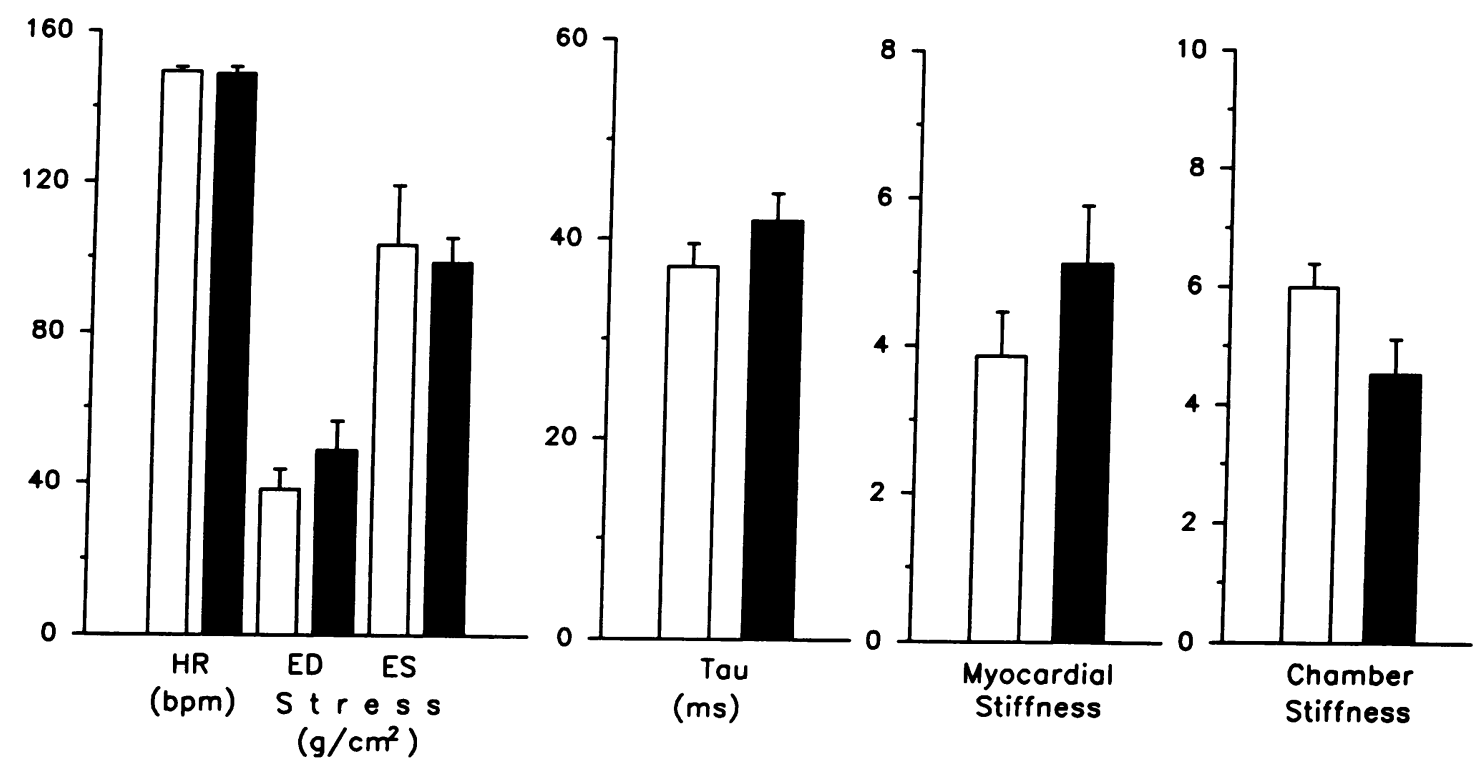

Figure 7. Changes in LV diastolic function ( $\tau\left[T_{\mathrm{D}}\right]$, myocardial stiffness, and chamber stiffness $\left.\left[\alpha_{\mathrm{n}}\right]\right)$ compared before and $3 \mathrm{wk}$ after rapid ventricular pacing. Values in the control state with elevated loading conditions to match those attained in the heart failure state were used for comparison. Heart rates at both the control and failure states were matched by left atrial pacing $(150 \mathrm{beats} / \mathrm{min})$. There were no differences in the three indexes of diastolic function in the control and failure states at matched load, in contrast to the persistent depression in systolic function noted in Fig. 6. Abbreviations as in Fig. 6.

load dependent $(23,44-49)$, it is also conceivable that the diastolic dysfunction could be due to the altered loading conditions, which are characteristic of heart failure.

In further support of this concept, prior studies have em- phasized the preload and afterload dependence of isovolumic relaxation $(23,45-49)$. These findings are consistent with and of a similar magnitude to those observed in our animals studied at control in which preload and afterload were increased simul-

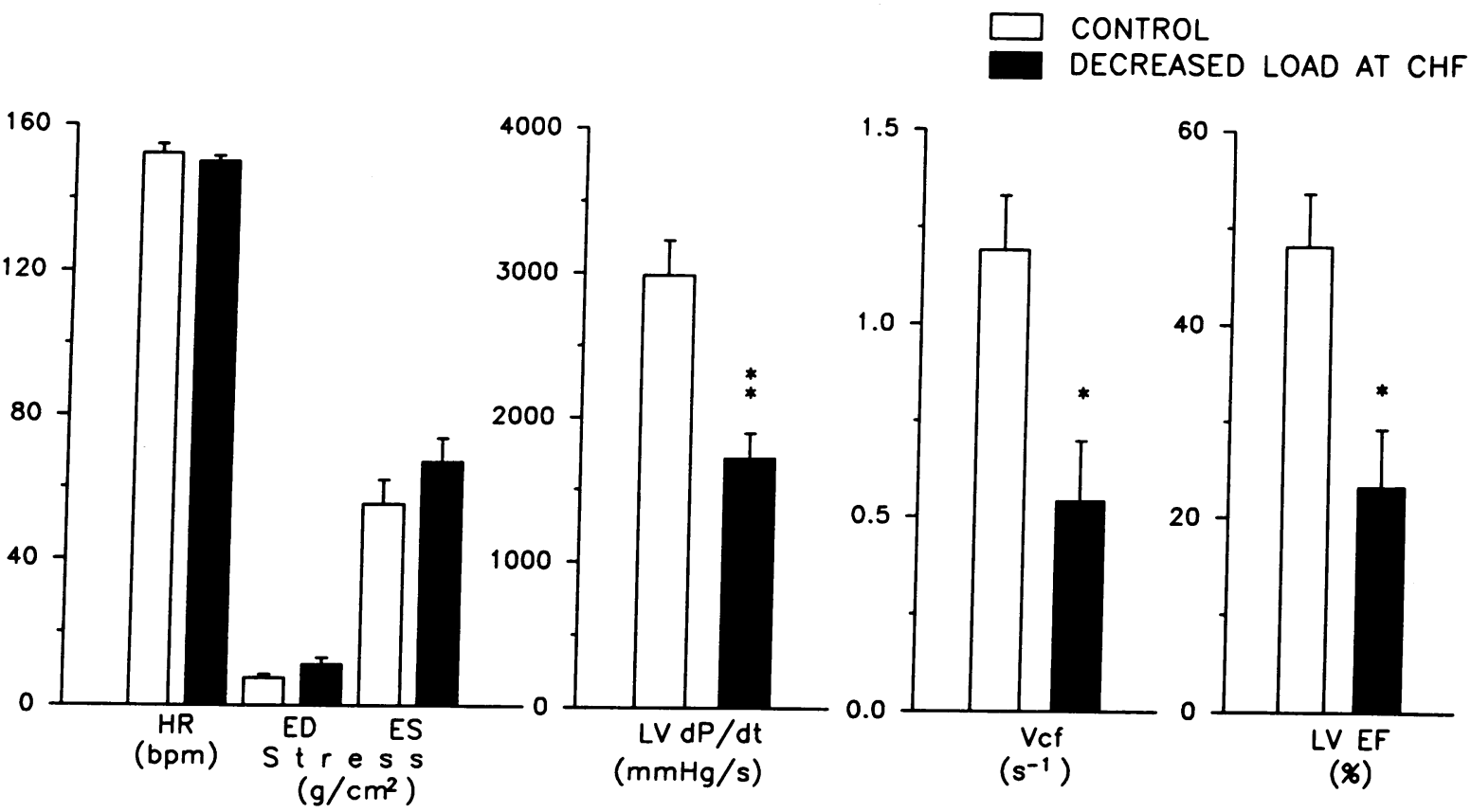

Figure 8. Changes in LV systolic function ( $\mathrm{LV} \mathrm{d} P / \mathrm{d} t, \mathrm{LV}$ mean velocity of circumferential fiber shortening [Vcf], and LV ejection fraction [EF]) compared before and $3 \mathrm{wk}$ after rapid ventricular pacing. Values in the heart failure state with reduced loading conditions were used to match those attained in the control state. Heart rates at both the control and failure states were matched by left atrial pacing ( $150 \mathrm{beats} / \mathrm{min})$. Even when LV end-diastolic and end-systolic stresses were reduced to control levels, LV systolic function was depressed significantly in the failure state. ${ }^{*} P<0.05$ vs. control; ${ }^{* *} P<0.01$ vs. control. Abbreviations as in Fig. 6. 


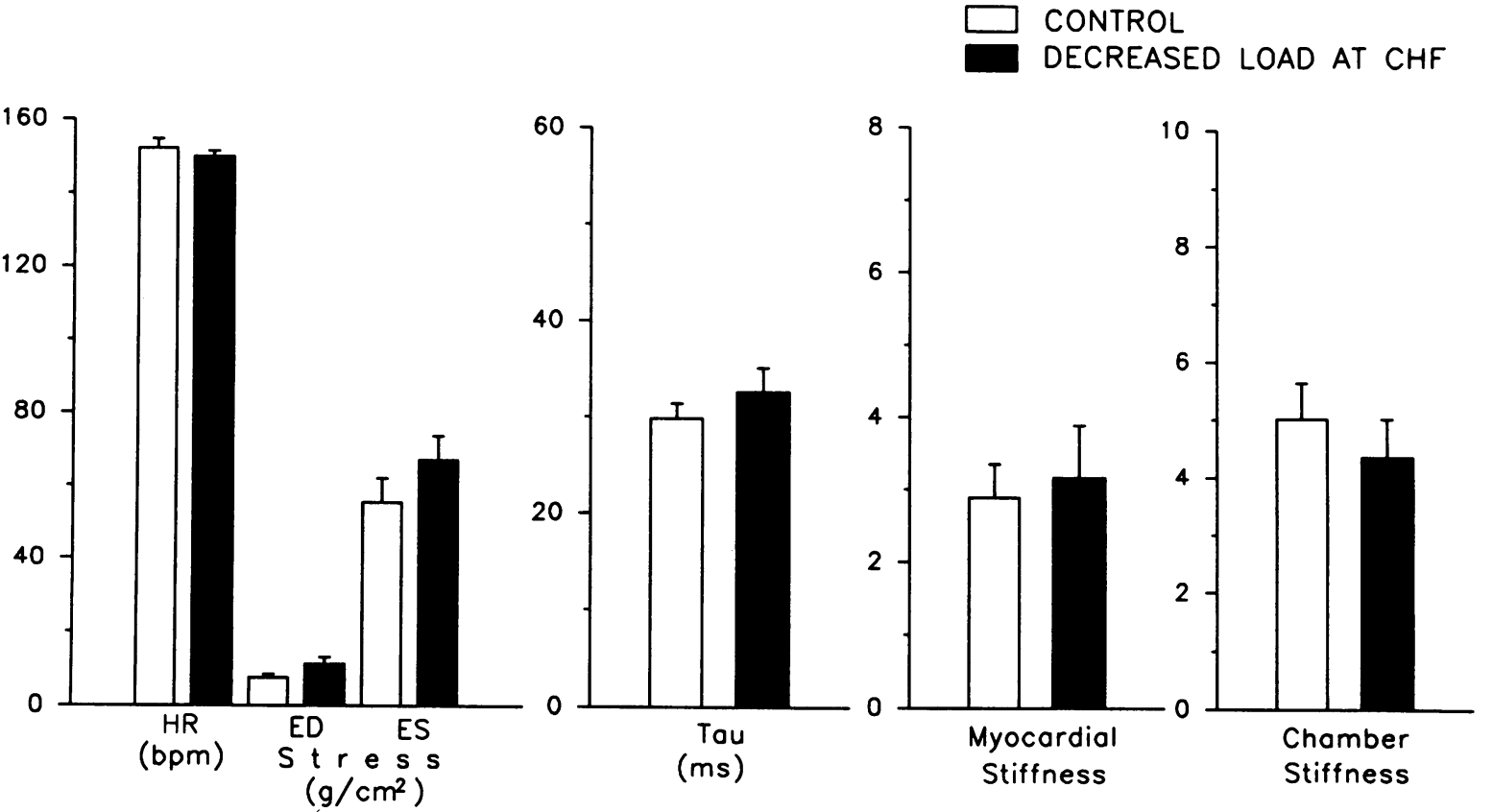

Figure 9. Changes in LV diastolic function ( $\tau\left[T_{\mathrm{D}}\right]$, myocardial stiffness, chamber stiffness $\left.\left[\alpha_{\mathrm{n}}\right]\right)$ compared before and 3 wk after rapid ventricular pacing. Values in the heart failure state with reduced loading conditions were used to match those attained in the control state. Heart rates at both the control and failure states were matched by left atrial pacing ( 150 beats $/ \mathrm{min})$. There were no differences in the three indices of diastolic function between the control and failure states at matched loading conditions in contrast to LV systolic function (Fig. 8). Abbreviations as in Fig. 6.

taneously. In addition, the study of Tomita et al. (12) suggested that increased afterload may be important in mediating LV diastolic dysfunction in heart failure. However, no study has attempted to ascertain whether the LV diastolic dysfunction that occurs in developing heart failure is reversible by normalizing the loading conditions.

Controversy exists as to the load dependence of different models of $\tau(22,23,45-51)$. Accordingly, we calculated $\tau$ in several ways (52). First, we used the method originally described by Weiss et al. (22). It has been suggested by others (51) that isovolumic pressure decay may not be monoexponential, because the slope of the relationship may vary between early relaxation as compared with later relaxation. We also employed two additional methods for calculating $\tau(23,52)$. Despite the various advantages and disadvantages of these different methods $(22,23,45-49)$, the results were qualitatively simi-

Table V. Pathology

\begin{tabular}{lccc}
\hline & $\begin{array}{c}\text { Sham } \\
\text { dogs } \\
(n=13)\end{array}$ & $\begin{array}{c}\text { Heart } \\
\text { failure } \\
\text { dogs } \\
(n=13)\end{array}$ & $\begin{array}{c}P \\
\text { value }\end{array}$ \\
\hline Body weight $(k g)$ & $28 \pm 1$ & $27 \pm 1$ & NS \\
LV + septum weight $(g)$ & $139 \pm 6$ & $141 \pm 10$ & NS \\
LV + septum weight/body weight & & & \\
$\quad(g / k g)$ & $5.0 \pm 0.1$ & $5.2 \pm 0.3$ & NS \\
RV weight $(g)$ & $49 \pm 2$ & $51 \pm 3$ & NS \\
RV weight/body weight $(g / k g)$ & $1.8 \pm 0.1$ & $1.9 \pm 0.1$ & NS \\
& & & \\
\hline
\end{tabular}

Values are mean \pm SEM.

Sham, sham-operated control dogs. lar with all three methods, i.e., $\tau$ was increased in heart failure, but the increase appeared to be load dependent. Thus, indexes of both $\tau$ and myocardial stiffness were load dependent and the observed abnormalities in these indexes during the development of heart failure could be ascribed to alterations in loading conditions.

In the present study, there were differential changes in chamber and myocardial stiffness during the development of heart failure (Fig. 4), i.e., myocardial stiffness increased but LV chamber stiffness remained unchanged. Also, chamber stiffness was not altered by varying the loading conditions (Figs. 6 and 8). It should be noted that these two measures of stiffness are conceptually different, because chamber stiffness is dependent on LV size and geometry, whereas myocardial stiffness reflects the mechanical properties of the myocardium itself $(53$, 54). Thus, in the calculation of chamber stiffness, the increase in myocardial stiffness is offset by the increase in operating volume of the ventricle. The increase in radial myocardial stiffness in the absence of increases in collagen at this stage in the heart failure process likely reflects the consequences of myocyte slippage (55) as well as other potential ultrastructural changes (56). Our finding of constancy in chamber stiffness was consistent with the report by Tomita et al. (12) using a similar model of heart failure and also consistent with other clinical findings in dilated cardiomyopathy $(36,42,57)$. In the present study, there was significant load dependence of indices of LV diastolic function in the control state. Effects of load dependence on indices of systolic function were not statistically significant. Thus, it appeared that LV diastolic function was more sensitive to loading conditions than LV systolic function in the control state under circumstances in which preload and afterload are increased simultaneously.

An important factor to consider in assessing LV diastolic 

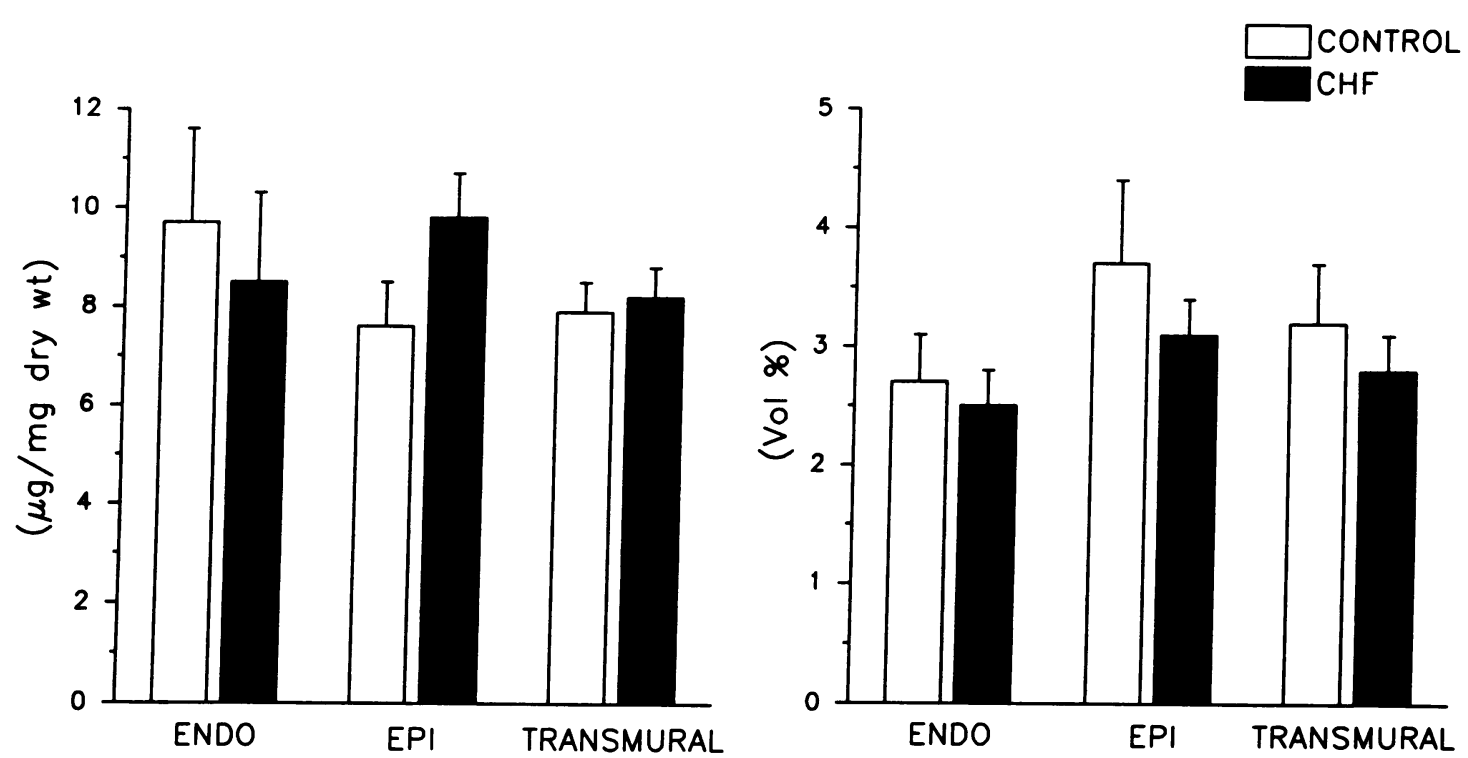

Figure 10. Transmural levels of tissue collagen are compared in sham-operated controls and dogs with heart failure, as assessed by hydroxyproline analysis (left) and quantitative histopathology (right). There were no significant differences in hydroxyproline concentration on the quantitative determination of connective tissue content between the two groups. Labels: ENDO, endomyocardial layer; EPI, epimyocardial layer; TRANSMURAL, transmural myocardium.

dysfunction is structural alterations that occur within the myocardium which may be responsible for altered physical properties leading to diastolic abnormalities $(43,58)$. Alterations in the interstitial matrix have been shown to be an important contributor to abnormalities in diastolic function observed in pressure overload hypertrophy related to both aortic banding $(27,58)$, functional aortic stenosis (53), and also in experimental models of longstanding perinephritic hypertension (59). However, we observed no quantitative differences in LV collagen content and the reversible nature of the LV diastolic functional abnormalities with correction of altered loading conditions was in keeping with the absence of significant histopathological changes. The findings in this study are in contrast to the

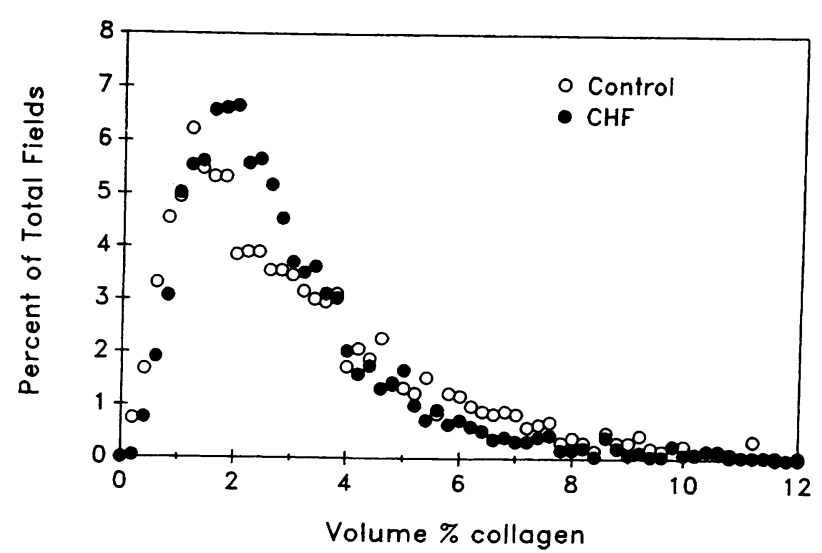

Figure 11. Histogram of the percent of total fields examined according to the volume percent collagen for each field measured in hearts from dogs with failure compared with those from sham-operated controls. Each field was analyzed using image analysis of picric acid sirius red-stained sections of LV myocardium. reports of Weber et al. (6) who observed quantitative increases in collagen content within the hearts of dogs exposed to 5-6 wk of rapid ventricular pacing. The differences may reflect the duration of the lesion, since our animals were paced for only 3 wk. It is conceivable that at later stages when these structural changes occur, alterations in LV diastolic function would not be totally load dependent, and would not be reversible by reducing preload and afterload. Weber et al. (6) also observed qualitative changes in myocardial collagen as early as $6 \mathrm{~h}$ after initiation of pacing. Assuming that the models are comparable between their laboratory and ours, it is possible to conclude that these early qualitative changes in collagen may neither result in quantitative increases in collagen nor alterations suffcient to induce diastolic dysfunction independent of loading conditions.

Another important myocardial structural change frequently accompanying heart failure is myocardial hypertrophy. It is well recognized that diastolic dysfunction can be observed in the hypertrophied heart $(35,36,53)$. However, in the model of pacing-induced heart failure used in the current investigation LV hypertrophy was not observed. If LV hypertrophy had occurred, it is also possible that the alterations in $\mathrm{LV}$ diastolic function would not have been corrected by reducing preload and afterload.

An additional influence on diastolic function that needs to be considered is the one of myocardial ischemia, inasmuch as myocardial ischemia per se can impair diastolic function (17, 60 ). A prior study in the model of pacing-induced heart failure found no significant alterations in coronary blood flow using coronary sinus catheters to measure blood flow (61). In a recent study, blood flow was found to decrease in pacing-induced failure in sedated pigs, in the face of an increased pressure-rate product (62). In our investigation, measurements of myocardial blood flow were made in the heart failure state and in a 
separate sham-operated group of dogs using radioactive microspheres (Table III). Transmural myocardial blood flow was reduced in heart failure, but there were no changes in the endo/ epi flow ratio. The preservation of a normal endo/epi ratio argues against ischemia, which is most often associated with preferential subendocardial hypoperfusion. Furthermore, it is possible that the reduction in baseline transmural myocardial blood flow reflects reductions in myocardial oxygen consumption. Whereas the indexes of myocardial oxygen consumption employed in this study, i.e., tension-time index and the triple product, were reduced in the heart failure state, these estimates are not as accurate as direct measures of myocardial oxygen consumption. As an example, when systolic wall stress was substituted for arterial pressure in the calculation of the triple product, no significant differences are observed in this index of myocardial oxygen consumption between the control and heart failure states. Finally, it should be noted that when heart rate and loading conditions were normalized in heart failure, transmural coronary blood flow was further reduced from $1.36 \pm 0.11$ to $1.18 \pm 0.12 \mathrm{ml} / \mathrm{min}$ per $\mathrm{kg}$. Despite the further reduction in myocardial blood flow, indexes of diastolic function were improved. Taken together, these findings suggest that myocardial ischemia is not likely the mechanism for the impairment in diastolic function at this stage in pacing-induced heart failure.

Recent in vitro studies exploring intracellular calcium handling by using the bioluminescent indicator, aequorin, have shown that the time to $90 \%$ relaxation was prolonged in trabeculae from the right ventricle of dogs with pacing-induced heart failure (63). However, the resting diastolic intracellular calcium levels, measured by fractional luminescence, were not significantly different between sham controls and dogs with heart failure. These findings are in keeping with the lack of significant diastolic dysfunction in the conscious state when loading conditions are normalized.

Another important observation is the fact that the development of LV systolic and diastolic abnormalities occur simultaneously in this model of pacing-induced heart failure. There has been considerable interest as to the timing of inotropic and lusitropic abnormalities in myocardial disease (3-5). Indeed, in certain states characterized by pressure overload hypertrophy, it is assumed that the diastolic abnormalities antedate the systolic abnormalities $(3,4)$. In this model of heart failure devoid of significant hypertrophy, it appears that the two abnormalities occur simultaneously. Most importantly, the abnormalities of both LV systolic and diastolic function were evident very early after the initiation of rapid ventricular pacing, before changes in LV geometry or ventricular dilatation were evident but when increases in LV systolic and diastolic wall stresses had occurred. It is also recognized that changes in $\tau$ vary inversely with contractility $(22,45,46,49)$. Thus, it is possible that the early increase in $\tau$ observed at $1 \mathrm{~d}$ after initiation of pacing was in part secondary to the reduced contractility. The studies at 3 wk of pacing induced heart failure clearly indicate that the changes in LV diastolic function were not dependent on depressed LV systolic function because, when loading conditions were matched, LV systolic function remained depressed, but LV diastolic dysfunction was no longer evident.

Recent studies (64), have demonstrated that diastolic indexes, i.e., $\tau$, remain sensitive to $\beta$-adrenergic stimulation with the intracoronary administration of dobutamine in dilated cardiomyopathy in humans whereas indexes of systolic function remain depressed. These findings raise the possibility that the improvement in indexes of diastolic function during normalization of loading conditions may reflect reflex mediated increases in adrenergic tone. While this is unlikely in view of depressed reflex control in heart failure $(65,66)$, this possibility was tested in two dogs with heart failure. In these two dogs in the presence of autonomic blockade with propranolol $(0.5 \mathrm{mg} / \mathrm{kg})$ and atropine methylbromide $(0.1 \mathrm{mg} / \mathrm{kg}), T_{\mathrm{L}}$ was $34 \mathrm{~ms}$ and fell to 21 ms when loading conditions were normalized. Thus, even with autonomic efferents blocked, reducing the loading conditions normalized $\tau$ in heart failure.

In summary, profound diastolic functional abnormalities occur in temporal association with systolic functional abnormalities in the model of pacing-induced heart failure in conscious, chronically instrumented dogs. Despite the early onset of these abnormalities, they are unassociated with structural or biochemical changes in interstitial collagen, evidence of myocardial ischemia, or ventricular hypertrophy. The diastolic functional abnormalities but not the systolic dysfunction are readily corrected by reducing the elevated end-systolic and diastolic stresses observed in the heart failure state. These data suggest that the markedly altered loading conditions themselves may contribute importantly to the expression of diastolic functional abnormalities but do not necessarily portend structural changes within the myocardium. However, the reversibility of these diastolic abnormalities with correction of loading conditions may not occur in heart failure of other etiologies where structural changes are more prominent. Nonetheless, the fact that major changes in diastolic function are entirely reversible in early stages of heart failure should be recognized when evaluating the effects of heart failure on diastolic function in experimental and clinical studies, where loading conditions cannot be controlled.

\section{Acknowledgments}

We appreciate the use of the programs for digitizing ventricular function from Dr. H. Pouleur and Mr. J. Sansdrap, Brussels, Belgium. We are grateful for the expert technical assistance of Pamela Powell and Catherine Sreenan.

This study was supported in part by National Institutes of Health grants HL38070, HL33107, and RR00168 and NASA Grant NAG 2 451. Dr. Komamura was initially supported by Otsuka Pharmaceutical Co., Ltd. and then supported by a Fellowship from the American Heart Association, Massachusetts Affiliate (13-449-890). Dr. Shannon is the recipient of a Clinician-Scientist Award of the American Heart Association.

\section{References}

1. Grossman, W. 1990. Diastolic dysfunction and congestive heart failure Circulation. 81(Suppl. III):III-1-III-7.

2. Katz, A. M. 1990. Interplay between inotropic and lusitropic effects of cyclic adenosine monophosphate on the myocardial cell. Circulation. 82(Suppl. I):I-7-I-11.

3. Bonow, R. O., D. R. Rosing, S. L. Bacharach, M. V. Green, K. M. Kent, L. C. Lipson, B. J. Maron, M. B. Leon, and S. E. Epstein. 1981. Effects of verapamil on left ventricular systolic function and diastolic filling in patients with hypertrophic cardiomyopathy. Circulation. 64:787-796.

4. Dougherty, A. H., G. V. Naccarelli, E. L. Gray, C. H. Hicks, and R. A Goldstein. 1984. Congestive heart failure with normal systolic function. Am. J. Cardiol. 54:778-782.

5. Souffer, R., D. Wohlbelernter, N. A. Vita, M. Amuchestegui, H. D. Sostman, H. J. Berger, and B. L. Zaret. 1985. Intact systolic left ventricular function in clinical congestive heart failure. Am. J. Cardiol. 55:1032-1036. 
6. Weber, K. T., R. Pick, M. A. Silver, G. W. Moe, J. S. Janicki, I. H. Zucker, and P. W. Armstrong. 1990. Fibrillar collagen and remodeling of dilated canine left ventricle. Circulation. 82:1387-1401.

7. Spinale, F. G., D. A. Hendrick, F. A. Crawford, A. C. Smith, Y. Hamada and B. A. Carabello. 1990. Chronic supraventricular tachycardia causes ventricular dysfunction and subendocardial injury in swine. Am. J. Physiol. 259(Heart Circ. Physiol. 28):H218-H229.

8. Coleman, H. N., R. R. Taylor, P. E. Pool, G. H. Whipple, J. W. Covel, J. J. Ross, and E. Braunwald. 1971. Congestive heart failure following chronic tachycardia. Am. Heart J. 81:790-798.

9. Morgan, D. E., C. W. Tomlinson, A. K. Qayumi, P. M. Toleikis, B. McConville, and W. R. E. Jamieson. 1989. Evaluation of ventricular contractility indexes in the dog with left ventricular dysfunction induced by rapid atrial pacing. J. Am. Coll. Cardiol. 14:489-495.

10. Chow, E., J. C. Woodard, and D. J. Farrar. 1990. Rapid ventricular pacing in pigs: an experimental model of congestive heart failure. Am. J. Physiol. 258(Heart Circ. Physiol. 27):H1603-H1605.

11. Shannon, R. P K. Komamura, B. S. Stambler, M. Bigaud, W. T. Manders, and S. F. Vatner. 1991. Alterations in myocardial contractility in conscious dogs with dilated cardiomyopathy. Am. J. Physiol. 260(Heart Circ. Physiol. 29):H1903-H1911.

12. Tomita, M., F. G. Spinale, F. A. Crawford, and M. R. Zile. 1991. Changes in left ventricular volume, mass, and function during the development and regression of supraventricular tachycardia-induced cardiomyopathy. Circulation. 83:635-644.

13. Rankin, J. S., P. A. McHale, C. E. Arentzen, D. Ling, J. C. Greenfield, and R. W. Anderson. 1976. Three-dimensional dynamic geometry of the left ventricle in conscious dogs. Circ. Res. 39:304-313.

14. Baig H. T. A. Patrick, and S. F. Vatner. 1977. Implantable pressure gauges for use in chronic animals. In Indwelling and Implantable Pressure Transducers. D. G. Flemming, W. H. Ko, and M. N. Neuman, editors. Chemical Rubber Co., Cleveland, OH. 35-43.

15. Pagani, M., H. Baig, A. Sherman, W. T. Manders, P. Quinn, T. A. Patrick, D. Franklin, and S. F. Vatner. 1978. Measurement of multiple small dimensions and study of arterial pressure-dimension relations in conscious animals. Am. J. Physiol. 235:H610-H617.

16. Fujii, A. M., R. J. Gelpi, I. Mirsky, and S. F. Vatner. 1988. Systolic and diastolic dysfunction during atrial pacing in conscious dogs with left ventricular hypertrophy. Circ. Res. 62:462-470.

17. Hittinger, L., R. P. Shannon, S. Kohin, A. S. Lader, W. T. Manders, T. A. Patrick, P. Kelly, and S. F. Vatner. 1989. Isoproterenol-induced alterations in myocardial blood flow, systolic and diastolic function in conscious dogs with heart failure. Circulation. 80:658-668.

18. Gelpi, R. J., A. Pasipoularides, N. Chase, A. S. Lader, T. A. Patrick, L Hittinger, R. P. Shannon, S. P. Bishop, and S. F. Vatner. 1991. Changes in diastolic cardiac function in developing and stable perinephritic hypertension in conscious dogs. Circ. Res. 68:555-567.

19. Sansdrap, J., H. Van Mechelen, H. Pouleur, and A. A. Charlier. 1981 CROPA: a research-oriented program for automatic processing of cardiovascula signals. In Computers in Cardiology. IEEE Computer Society, Florence. 433436.

20. Starling, M. R., D. G. Montgomery, G. B. J. Mancini, and R. A. Walsh. 1987. Load independence of the rate of isovolumic relaxation in man. Circula tion. 76:1274-1281.

21. Mirsky, I. 1974. Review of various theories for evaluation of left ventricular wall stress. In Cardiac Mechanics: Physiological, Chemical, and Mathematica Considerations. I. Mirsky, D. N. Chiston, and H. Sandler, editors. John Wiley \& Sons, Inc., New York. 381-409.

22. Weiss, J. L., J. W. Fredricksen, and M. L. Weisfeldt. 1976. Hemodynamic determinants on the time-course of fall in canine left ventricular pressure. J. Clin. Invest. 58:751-760.

23. Murgo, J. P., W. E. Craig, and A. Pasipoularides. 1988. Evaluation of time course of left ventricular isovolumic relaxation in man. In Diastolic Relaxation of the Heart. W. Grossman and B. H. Lorrell, editors. Nijhoff Publishing, Boston 125-132.

24. Bevington, P. R. 1969. Data Reduction and Error Analysis for the Physical Sciences. McGraw-Hill, Inc., New York. 204-206.

25. Mirsky, I. 1984. Assessment of diastolic function: suggested methods and future considerations. Circulation. 69:836-841.

26. Mirsky, I. 1979. Elastic properties of the myocardium: a quantitative approach with physiological and clinical applications. In Handb. Physiol. (Sect. 2 , Cardiovasc. Syst.). R. M. Berne, N. Sperelakis, and S. R. Geiger, editors. 1:497531.

27. Hittinger, L., R. P. Shannon, S. P. Bishop, R. J. Gelpi, and S. F. Vatner. 1989. Subendomyocardial exhaustion of blood flow reserve and increased fibrosis in conscious dogs with heart failure. Circ. Res. 65:971-980.

28. Woessner, J. F. 1961. The determination of hydroxyproline in tissue and protein samples containing small proportions of this amino acid. Arch. Biochem. Biophys. 93:440-447.
29. Armitage, P. 1977. Statistical Methods in Medical Research. John Wiley \& Sons, Inc., New York. 504 pp.

30. Gaasch, W. H., W. E. Battle, A. A. Oboler, J. S. Banas, Jr., and H. J. Levine. 1972. Left ventricular stress and compliance in man with special reference to normalized ventricular function curves. Circulation. 45:746-762.

31. Mirsky, I., P. F. Cohn, J. A. Levine, R. Gorlin, M. V. Herman, T. H. Kreulen, and E. H. Sonnenblick. 1974. Assessment of left ventricular stiffness in primary myocardial disease and coronary artery disease. Circulation. 50:128136.

32. Gaasch, W. H., J. S. Cole, M. A. Quinones, and J. K. Alexander. 1975. Dynamic determinants of left ventricular diastolic pressure-volume relations in man. Circulation. 51:317-323.

33. Hess, O. M., J. Grimm, and H. P. Krayenbuehl. 1979. Diastolic simple elastic and viscoelastic properties of the left ventricle in man. Circulation. 59:1178-1187.

34. Grossman, W., L. P. McLaurin, and E. L. Rolett. 1979. Alterations in left ventricular relaxation and diastolic compliance in congestive cardiomyopathy. Cardiovasc. Res. 13:514-522.

35. Hess, O. M., J. Schneider, R. Koch, C. Bamert, J. Grimm, and H. P. Krayenbuehl. 1981. Diastolic function and myocardial structure in patients with myocardial hypertrophy: special reference to normalized viscoelastic data. Circulation. 63:360-371.

36. Grossman, W., L. P. McLaurin, and M. A. Stefadouros. 1974. Left ventricular stiffness associated with chronic pressure and volume overloads in man. Circ. Res. 35:793-800.

37. Katayama, K., T. Tajimi, B. D. Guth, M. Matsuzaki, J.-D. Lee, R. Seitelberger, and K. L. Peterson. 1988. Early diastolic filling dynamics during experimental mitral regurgitation in the conscious dog. Circulation. 78:390-400.

38. Dawson, M. J., D. G. Gadian, and D. R. Wilkie. 1980. Mechanical relaxation rate and metabolism studied in fatiguing muscle by phosphorus nuclear magnetic resonance. J. Physiol. (Lond.). 299:465-484.

39. Renlund, D. G., E. G. Lakatta, E. D. Mellits, and G. Gerstenblith. 1985 Calcium-dependent enhancement of myocardial diastolic tone and energy utilization dissociates systolic work and oxygen consumption during low sodium perfusion. Circ. Res. 57:876-888.

40. Bers, D. M., and J. H. B. Bridge. 1989. Relaxation of rabbit ventricular muscle by $\mathrm{Na}-\mathrm{Ca}$ exchange and sarcoplasmic reticulum calcium pump. Ryanodine and voltage sensitivity. Circ. Res. 65:334-342.

41. Nayler, W. G., and A. Williams. 1978. Relaxation in heart muscle: some morphological and biochemical considerations. Eur. J. Cardiol. 7(Suppl.):35-50.

42. Bortone, A. S., O. M. Hess, A. Chiddo, A. Gaglione, N. Locuratolo, G. Caruso, and P. Rizzon. 1989. Functional and structural abnormalities in patients with dilated cardiomyopathy. J. Am. Coll. Cardiol. 14:613-623.

43. Nakayama, Y., G. Shimizu, Y. Hirota, T. Saito, Kino Masaya, Y. Kitaura, and K. Kawamura. 1987. Functional and histopathologic correlation in patients with dilated cardiomyopathy: an integrated evaluation by multivariate analysis. J. Am. Coll. Cardiol 10:186-192.

44. Pasipoularides, A., I. Mirsky, O. M. Hess, J. Grimm, and H. P. Krayenbuehl. 1986. Myocardial relaxation and passive diastolic properties in man. Circulation. 74:991-1001.

45. Karliner, J. S., M. M. LeWinter, F. Mahler, R. Engler, R. A. O'Rourke. 1977. Pharmacologic and hemodynamic influences on the rate of isovolumic left ventricular relaxation in the normal conscious dog. J. Clin. Invest. 60:511-521.

46. Gaasch, W. H., A. S. Blaustein, C. W. Andrias, R. P. Donahue, and B. Avitall. 1980. Myocardial relaxation. II. Hemodynamic determinants of rate of left ventricular isovolumic pressure decline. Am. J. Physiol. 239(Heart Circ. Physiol. 8):H1-H6.

47. Blaustein, A. S., and W. H. Gaasch. 1983. Myocardial relaxation. VI. Effects of $\beta$-adrenergic tone and asynchrony on LV relaxation rate. Am. J. Physiol. 244(Heart Circ. Physiol. 13):H417-H422.

48. Perlini, S., F. Soffiantino, C. Farilla, P. Solda, A. Calciati, M. Paro, G. Finardi, and L. Bernardi. 1988. Load dependence of isovolumic relaxation in intact heart: facts or artifacts? Cardiovasc. Res. 22:47-54.

49. Cheng, C.-P., G. L. Freeman, W. P. Santamore, M. S. Constantinescu, and W. C. Little. 1990 . Effect of loading conditions, contractile state, and heart rate on early diastolic left ventricular filling in conscious dogs. Circ. Res. 66:814-823.

50. Gaasch, W. H., J. D. Carroll, A. S. Blaustein, and O. H. L. Bing. 1986. Myocardial relaxation: effects of preload on the time course of isovolumetric relaxation. Circulation. 73:1037-1041.

51. Yellin, E. L., M. Hori, C. Yoran, E. H. Sonnenblick, S. Gabbay, and R. W. $M$. Frater. 1986. Left ventricular relaxation in the filling and nonfilling intact canine heart. Am. J. Physiol. 250:H620-629.

52. Martin, G., J. V. Gimeno, J. Cosin, and M. I. Guillem. 1984. Time contant of isovolumic pressure fall: new numerical approaches and significance. Am. J. Physiol. 247(Heart Circ. Physiol. 16):H283-H294.

53. Hess, O. M., M. Ritter, J. Schneider, J. Grimm, M. Turina, and H. P. Krayenbuehl. 1984. Diastolic stiffness and myocardial structure in aortic valve disease before and after valve replacement. Circulation. 69:855-865.

54. Mirsky, I., J. M. Pfeffer, M. A. Pfeffer, and E. Braunwald. 1983. The 
contractile state as the major determinant in the evolution of left ventricular dysfunction in the spontaneously hypertensive rat. Circ. Res. 53:767-778.

55. Zellner, J. L., F. G. Spinale, D. M. Eble, K. W. Hewlett, and F. A. Crawford. 1991. Alterations in myocyte shape and basement membrane attachmen with tachycardia-induced heart failure. Circ. Res. 69:590-600.

56. Spinale, F. G., J. L. Zellner, M. Tomita, F. A. Crawford, and M. R. Zile 1991. Relation between ventricular myocyte remodelling with the developmen and regression of supraventricular tachycardia-induced cardiomyopathy. Circ Res. 69:1058-1067.

57. Katayama, K., M. Matsuzaki, M. Khono, T. Fujii, N. Ohtani, S. Yatabe H. Ogawa, M. Ozaki, Y. Matsuda, and R. Kusukawa. 1990. Global and regiona diastolic filling dynamics in compensated dilated cardiomyopathy. Jpn. Circ. J. 54:624-635.

58. Jalil, J. E., C. W. Doering, J. S. Janicki, R. Pick, S. G. Shroff, and K. T. Weber. 1989. Fibrillar collagen and myocardial stiffness in the intact hypertrophied rat left ventricle. Circ. Res. 64:1041-1050.

59. Weber, K. T., J. S. Janicki, S. G. Shroff, R. Pick, R. M. Chen, and R. I. Bashey. 1988. Collagen remodeling of the pressure-overloaded, hypertrophied nonhuman primate myocardium. Circ. Res. 62:757-765.

60. Aroesty, J. M., R. G. McKay, G. V. Heller, H. D. Royal, A. V. Als, and W. Grossman. 1985. Simultaneous assessment of left ventricular systolic and diastolic dysfunction during pacing-induced ischemia. Circulation. 71:889-900.
61. Wilson, J. R., P. Douglas, W. Hickey, V. Lanoce, N. Ferraro, A. Muhammad, and N. Reichek. 1987. Experimental congestive heart failure produced by rapid ventricular pacing in the dog: cardiac effects. Circulation. 75:857-867.

62. Spinale, F. G., J. L. Zellner, M. Tomita, G. E. Tempel, F. A. Crawford, and M. R. Zile. 1991. Tachycardia-induced cardiomyopathy: effects on blood flow and capillary structure. Am. J. Physiol. 261(Heart Circ. Physiol. 30):H140 H148.

63. Perreault, C. L., R. P. Shannon, K. Komamura, S. F. Vatner, and J. P. Morgan. 1992. Abnormalities in intracellular calcium regulation and contractile function in myocardium from dogs with pacing-induced heart failure. J. Clin. Invest. 89:932-938.

64. Parker, J. D., J. S. Landzberg, J. A. Bittl, I. Mirsky, and W. S. Colucci. 1991. Effects of $\beta$-adrenergic stimulation with dobutamine on isovolumic relaxation in the normal and failing human left ventricle. Circulation. 84:1040-1048.

65. Eckberg, D. L., M. Drabinsky, and E. Braunwald. 1971. Defective cardiac parasympathetic control in patients with heart disease. N. Engl. J. Med. 285:877883.

66. Higgins, C. B., S. F. Vatner, D. L. Eckberg, and E. Braunwald. 1972. Alterations in the baroreceptor reflex in conscious dogs with heart failure. J. Clin. Invest. 51:715-724. 